San Jose State University

SJSU ScholarWorks

Master's Theses

Master's Theses and Graduate Research

Spring 2018

\title{
Effects of a Preschool Arts Curriculum on Social and Emotional Competence
}

Sarah Rose Henderson

San Jose State University

Follow this and additional works at: https://scholarworks.sjsu.edu/etd_theses

\section{Recommended Citation}

Henderson, Sarah Rose, "Effects of a Preschool Arts Curriculum on Social and Emotional Competence" (2018). Master's Theses. 4908.

DOI: https://doi.org/10.31979/etd.69x5-gua5

https://scholarworks.sjsu.edu/etd_theses/4908

This Thesis is brought to you for free and open access by the Master's Theses and Graduate Research at SJSU ScholarWorks. It has been accepted for inclusion in Master's Theses by an authorized administrator of SJSU ScholarWorks. For more information, please contact scholarworks@sjsu.edu. 


\title{
EFFECTS OF A PRESCHOOL ARTS CURRICULUM ON SOCIAL AND EMOTIONAL COMPETENCE
}

\author{
A Thesis \\ Presented to \\ San José State University \\ In Partial Fulfillment \\ of the Requirements for the Degree \\ Master of Arts
}

The Faculty of the Department of Child and Adolescent Development

by

Sarah R. Henderson

May 2018 
(C)2018

Sarah R. Henderson

ALL RIGHTS RESERVED 
The Designated Thesis Committee Approved the Thesis Titled

\title{
EFFECTS OF A PRESCHOOL ARTS CURRICULUM ON SOCIAL AND EMOTIONAL COMPETENCE
}

by

Sarah R. Henderson

\section{APPROVED FOR THE DEPARTMENT OF CHILD AND ADOLESCENT DEVELOPMENT}

\section{SAN JOSÉ STATE UNIVERSITY}

May 2018

\begin{abstract}
Ellen Middaugh, Ph.D. Department of Child and Adolescent Development Robin Love, Ph.D. Department of Child and Adolescent Development Maureen Smith, Ph.D. Department of Child and Adolescent Development
\end{abstract}




\section{ABSTRACT \\ EFFECTS OF A PRESCHOOL ARTS CURRICULUM ON SOCIAL AND EMOTIONAL COMPETENCE}

by Sarah R. Henderson

This study investigated the extent to which low-income preschool children's social, emotional, and behavioral competence improved after engaging in a six-week-long arts program. Participants included 46 students of three, four, and five years of age in two low-income, state-funded classrooms in the San Francisco Bay Area. Analyses of children's scores on SCBE-80 measures of Social Competence and Egotistic-Prosocial showed statistically significant change from the pretest to the posttest. Teacher survey report of students' frequency in social adaptation and enjoyment of the arts suggested that teachers observed social improvements in the classroom that were consistent with SCBE80 results in Social Competence. Student interview results in frequency in emotional adjustment showed that children were more likely to identify their emotions, as was consistent with SCBE-80 results in Egotistic-Prosocial. Teachers reported that the arts program was a positive addition to the classroom and that they would be likely to continue the arts program in their classrooms if given the option. Taken together these findings lend empirical support to the argument that arts education can lead to social and emotional improvements in low-income populations. Further study of the critical elements of art program structure or type is recommended. 


\section{ACKNOWLEDGMENTS}

I would like to thank my advisor, Dr. Robin Love, for the support, advice, and guidance I received from her. Dr. Love’s patience, knowledge, encouragement, and flexibility facilitated my research process. I would not have been able to complete this thesis without her expertise. I would also like to thank Dr. Ellen Middaugh and Dr. Maureen Smith for their time, wisdom, patience, and guidance. In addition, I would like to thank Dr. Nadia Sorkhabi for taking the time to offer advice on my research.

I would also like to thank Ms. Patricia Perla, Ms. Anna Franceschi, Ms. Elena Pineda, Ms. Gabriela Nunez, Ms. Rosa Juarez, and Ms. Graciela Patino from the Garfield Child Development Center for opening their classrooms to me, assisting with rating scales, and contributing their knowledge and expertise to the study. In addition, I would like to extend a thank you to Ms. Edna Carmona for her support and encouragement with this project.

I would like to thank and acknowledge the Art in Action team: Ms. Rachel Dodd, Ms. Katie O’Malley, Ms. Mary Ellison, and Mr. Jimmy Vo, for their support, flexibility, patience, and quick thinking. I would also like to thank the docents, Ms. Savannah Feriante and Mr. Jeffrey Petromilli, for their cooperation and participation in teaching the program.

I would like to acknowledge the GoFundMe supporters and particularly my uncle, Mark Fox, for their financial support of my research. Finally, I would like to thank Abe Martinez for his endless support, patience, and belief in me. 


\section{TABLE OF CONTENTS}

Table of Contents.................................................................................................... vi

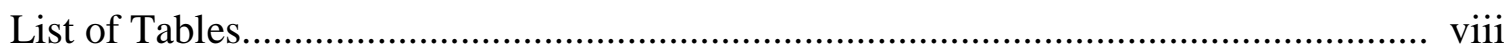

Chapter 1

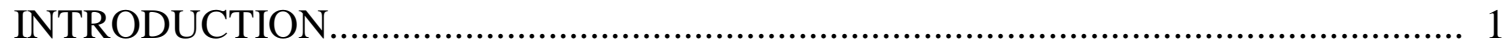

Chapter 2

THEORETICAL FRAMEWORK............................................................................. 6

Chapter 3

REVIEW OF THE LITERATURE................................................................... 9

Arts and Development...................................................................................... 9

Arts and Social Development.................................................................... 10

Arts and Emotional Development.................................................................. 15

Poverty and Development............................................................................. 20

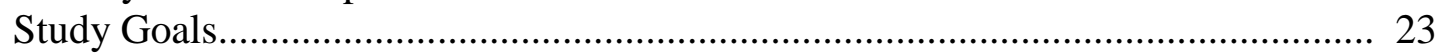

Chapter 4

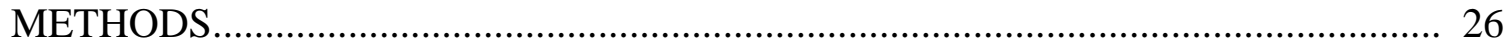

Participant Population......................................................................................... 26

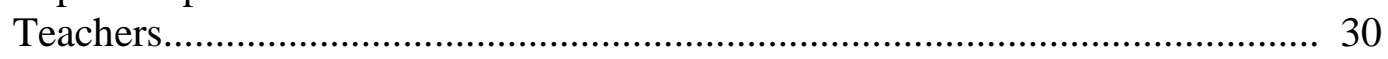

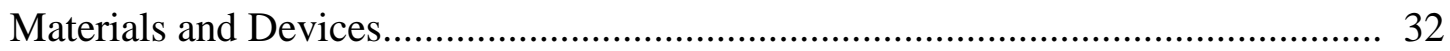

Basic Scales........................................................................................ 32

Depressive-Joyful.............................................................................. 33

Anxious-Secure.................................................................................... 33

Angry-Tolerant.................................................................................... 33

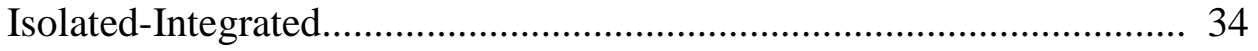

Aggressive-Calm.............................................................................. 34

Egotistic-Prosocial.............................................................................. 35

Oppositional-Cooperative....................................................................... 35

Dependent-Autonomous...................................................................... 35

Summary Scales......................................................................................... 36

Social Competence.............................................................................. 36

Internalizing Problems........................................................................... 36

Externalizing Problems......................................................................... 36

General Adaptation.......................................................................... 37

Culminating Teacher Survey......................................................................... 37

Student Interview....................................................................................... 38

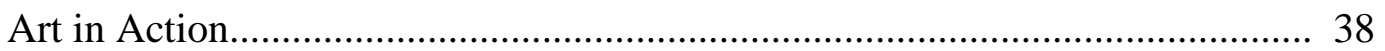

Teaching and Volunteers...................................................................... 40

Curriculum........................................................................................ 40 


\section{TABLE OF CONTENTS (continued)}

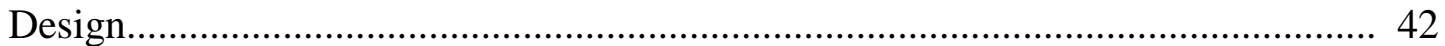

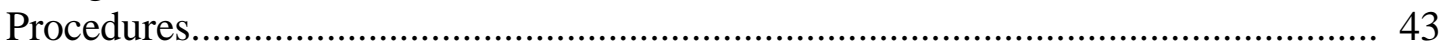

Chapter 5

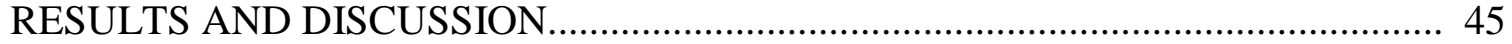

Difference in Outcomes by Gender.............................................................. 51

Difference in Outcomes by Age................................................................ 51

Student Interview Results........................................................................... 51

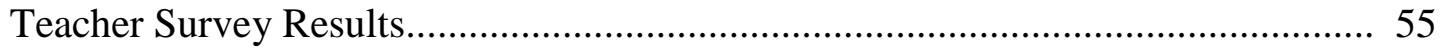

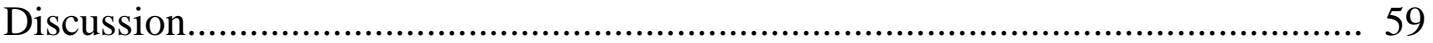

Chapter 6

CONCLUSION

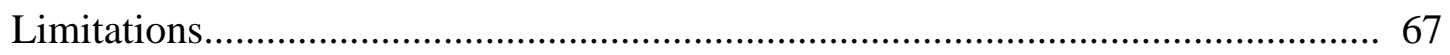

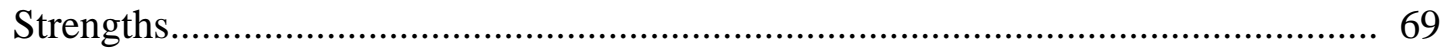

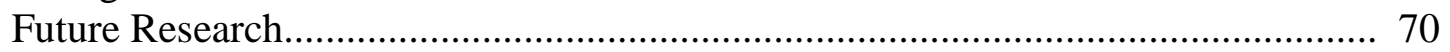

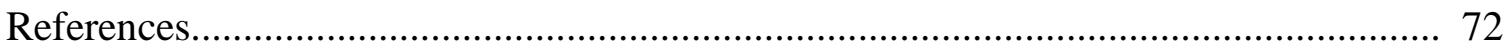

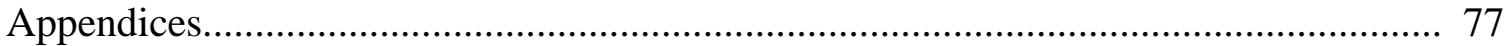

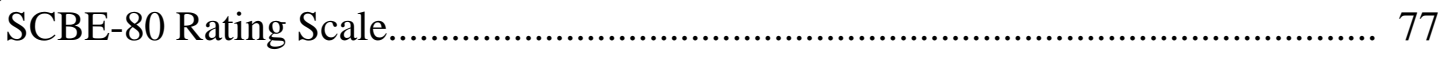

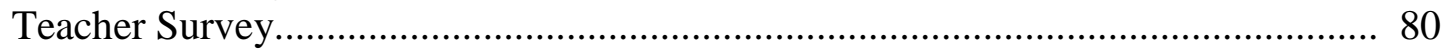




\section{LIST OF TABLES}

Table 1. Garfield CDC Classroom Demographic Data......................................... 29

Table 2. Garfield CDC Teacher Demographic Data......................................... 31

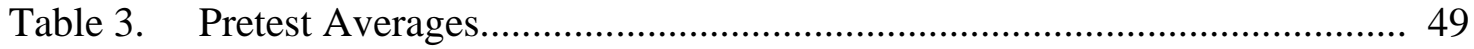

Table 4. Combined Data Paired Samples T-Test.............................................. 50

Table 5. Student Interview Data............................................................... 57

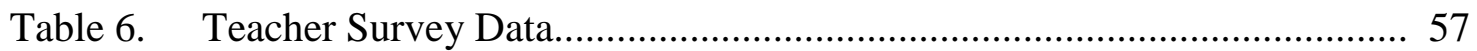


Chapter 1

\section{Introduction}

Children and families in the San Francisco Bay Area have disparate income levels and poverty status. In San Mateo County, where the population of this study resides, 16.6\% of families live in poverty (Public Policy Institute of California, 2017). Of this 16.6\%, Latinos have dramatically higher poverty rates: $27 \%$ of Latino families live in poverty compared to $13.5 \%$ of white families. Children who live in poverty face unique challenges, such as lower instances of prosocial behavior and higher rates of aggression, as compared children with access to more resources, opportunities, and social capital (Locke, Miller, Seifer, \& Heinze, 2015). Children who live in disadvantaged environments may struggle with school readiness skills. They may be predisposed for poor school performance due to difference in social and emotional learning, leading to difficult behavior in the classroom and subsequent negative relationships with teachers and peers (Fantuzzo, Bultosky-Shearer, McDermott, McWayne, Frye, \& Perlman, 2007). Children who grow up in poverty are at greater risk for disciplinary action in school, missing out on educational opportunities, less positive relationships with teachers and peers, higher dropout rate, and risk for substance abuse, negative mental health diagnoses, homelessness, and continued poverty throughout life (Williams Shanks \& Robinson, 2013). The trends noted above may be mitigated by positive social and emotional connections early in life, in a school environment, to shift life outcomes in a more positive direction (Brouillette, 2010). Therefore, interventions in preschool may be effective for teaching children positive socio-emotional skills. This study utilizes this idea 
by implementing a preschool arts intervention to build positive socio-emotional connections and show the potential effects of arts on behavior, bringing positive interventions to children within a school environment. However, positive interventions in a school environment are most effective if the school environment itself promotes engagement in learning (Castro, Granlund, \& Almqvist, 2015).

Classroom quality can define learning opportunities for preschool children (Castro, Granlund, \& Almqvist, 2015). Children who live in poverty tend to enroll in their neighborhood schools, which leads to concentrated numbers of low-income families within the district (Williams Shanks \& Robinson, 2013). Districts within low-income neighborhoods have low funding for school supplies and extracurriculars. California laws, such as Proposition 13, have led to program cuts. Proposition 13 focused on property taxes, but education funding waned as an unintended consequence (Public Policy Institute of California, 1998). A portion of the property tax that is collected by the state is allocated to school districts, but school funding fluctuated between 1985 and 1990, leading to Proposition 98, which established a minimum amount of funding required from the state to public schools (Public Policy Institute of California, 1998). However, Proposition 98 affected the state's overall expenditures, and spending more on schools meant less funding was allocated to other state projects. Consequently, the state would allocate the exact minimum to the school districts. This minimum is calculated using General Fund revenues, state population, K-12 average daily attendance and, most notably, personal income and local property taxes (Public Policy Institute of California, 1998). Therefore, the schools in the lowest-earning districts receive the lowest amounts 
of funding. The first programs to be cut in these low-income districts are art and music programs (California Alliance for Arts Education, 2005). Although Proposition 13 was passed 30 years ago in California, schools are still struggling to implement arts programs (California Alliance for Arts Education, 2005). Currently, the federal education budget is set to be cut by 13 percent, targeting afterschool programs, which serve as a protective factor for children in poverty, and often host arts activities (San Francisco Chronicle, 2017). While children in poverty still have access to subjects such as math, science, and social studies, the first programs to be removed are the higher-order subjects such as art and music. Because art and music cannot be tested using standardized tests, districts put less funding into developing strong arts curricula. However, the arts are a notable avenue for the development of social, emotional, and behavioral competence (Mcclure, Tarr, Thompson, \& Eckhoff, 2017).

Children who live in poverty are, arguably, the subjects with the highest need for arts intervention services. Younger children show higher problem behavior and lower levels of regulation, which is consistent with developmental expectations. However, young children living in poverty experience elevated risk for problem behavior and difficulty regulating emotions that persists over time (Holtz, Fox, \& Meurer, 2015). Children who have difficulties with behavioral self-control are more likely to disrupt the classroom environment, leading to negative relationship outcomes with teachers, and are less successful in engaging with peers, leading to negative relationship outcomes (Fantuzzo et al., 2007). Children with non-normative socio-emotional development may benefit from 
interventions which work to improve adjustment and behavioral outcomes in the environment.

Research has connected the art-making process with improved social and emotional development, adjustment, and behavioral outcomes (Beh-Pajooh, Abdollahi, \& Hosseinian, 2018). Children and adults can use the arts to improve emotions, social functioning, and behavior. These connections are repeated anecdotally by scholars and laymen alike but are often supported by studies wherein feelings are measured by participant report, as represented by Klorer and Robb (2012) in their study of an arts program collaboration between graduate students and a Head Start classroom. The graduate students implemented art therapy tactics in the classroom and then asked teachers how they felt about the program. The teachers were also provided a scale from 1 to 10 on which to rate the quality of the program, with 1 being "poor” and 10 being “excellent”. Although this method is useful to determine teachers' feelings of how their class responded to the program, the method does not allow for objective measurement of where children's behavioral skills are at before and after the program. From a research standpoint, qualitative connections are important, but they are do not always determine defined improved outcomes. In some ways, this is positive, because arts research is largely participant-driven and focused on perceived outcomes from before, during, and after treatment. Using self-report and interview data is useful to understand individual differences in response to the intervention. However, empirical data showing differences between children's outcomes from before being exposed to an arts programs versus children's outcomes when there is no arts program implemented, in conjunction with 
self-report and interview, would help to demonstrate the objective effectiveness of these programs.

Overall, researchers, such as Sitzer and Stockwell (2015), outline the same general themes: the arts help children to feel empowered, confident, calm, and focused. Sitzer and Stockwell (2015) utilized a 14-week arts therapy curriculum with students ranging from 9 to 12 years of age. The researchers utilized a 7-point, self-report Likert scale called The Wellness Inventory to examine changes in socio-emotional measures such as ability to compromise, ability to maintain a positive attitude, ability to tolerate frustration, ability to communicate effectively, and ability to maintain self-confidence. The selfreport data of the students is valuable in contextualizing how students received and processed the art therapy curriculum. Art studies provide useful insights into how teachers and students are feeling in response to programs and support the hypothesis that the arts improve socio-emotional learning and adjustment. In conjunction with teacher and student opinions, however, a rating scale which documents socio-emotional and behavioral qualities of the students in the classroom can add dimension and context to teacher and student report results. 


\section{Chapter 2}

\section{Theoretical Framework}

The arts have been explored as a pedagogical framework before. John Dewey (1938a) posits that children should be educated to analyze what qualities are common to the human experience across cultures, expressing that creating and assessing art ties in with educational goals such as empathy, moral thinking, open-mindedness, and independence. Dewey (1938b) expresses that art provides sensory experiences which elevate understanding of the human experience, providing insight into the hidden processes of self and others. For children, who are learning to process society and how they fit into it, arts education provides opportunities to explore their own daily lives on a deeper level. By making active decisions during the art-making process and transferring feelings and experiences into a tangible product, children learn power over their creative and emotional processes (Dewey, 1925). Dewey (1925) explains that students have the desire to communicate with others, the desire to construct things, the desire to express themselves, and the desire to investigate. Facilitated by arts education, students are able to utilize their hands, bodies, and eyes in a multi-faceted, holistic method of learning that addresses these natural educational desires. Creativity and expression are as basic to humanity as literacy or mathematics, showing the importance of a rounded education that includes a multitude of avenues for learning and complex thought (Dewey \& Dewey, 1915). Including art as a core subject in schools allows for equity in learning by providing all children with the opportunity to access a transformative experience through self-inquiry during the creative process. 
Dewey (1934) explains that the arts offer an opportunity for equitable education. Art is everywhere, within every culture, and within many different classes of people. All people are equal as creators and as viewers, bringing their own perspectives to the fabric of artistic expression by detailing their daily internal lives. Art expresses global experiences and can help to remove biases (Dewey, 1938b). Artists express cultural aspirations and personal experiences through their artwork. Children can learn about others by viewing and assessing artistic content, feeling emotions as a response to viewing art, and finding common experiences with the artist in order to develop empathy.

Dewey (1934) posits that art allows children to access a self not consciously known and to privately make independent decisions on how to express thoughts, feelings, and experiences in a visual context. These secret and personal choices made by artists are called the "experience” by Dewey (as cited in Goldblatt, 2006). The experience of creating and viewing art allows for an escape from the expectations of the environment immediately around the student and creates an imaginary space wherein children can dream, express, and privately plan. The experience of viewing art encourages students to practice Dewey's concept of "social imagination and conception” (as cited in Goldblatt, 2006, p. 23), which refers to thinking about and planning of future events. Practicing and planning privately may allow for more thoughtful control of behavior in the classroom. Thinking about and planning events ahead of time is a skill for preschoolers, since sporadic, aggressive, or unplanned behavior may lead to negative social outcomes (Locke et al., 2015). Children with low socioeconomic status are more likely to show such behaviors, which can lead to social exclusion in the classroom (Locke et al., 2015). 
Dewey views art as a universal tool for communication, expression, and learning, which does not exclude students due to skill or socioeconomic status (Goldblatt, 2006). In the context of this study, Dewey's theory supports the need for equity in education and for using the arts as an avenue to enhance empathetic thinking, independent decisionmaking, and social imagination and conception. This study will assess the ways in which arts education can enhance socio-emotional factors and serve as an intervention for children with low socioeconomic status. 
Chapter 3

\section{Review of the Literature}

\section{Arts and Development}

The arts have been shown to enhance development in social, emotional, and behavioral realms (Sitzer \& Stockwell, 2015). The arts can help students with social connections with teachers, parents, and peers. Schools can also include the arts as a form of emotional and behavioral intervention for students (Isis, Bush, Siegel, \& Ventura, 2010). Feeling successful at art-making and building relationships with peers and teachers through communicating about art can help children to gain social skills in a lowpressure forum (Klorer \& Robb, 2012). Children who develop more competent social skills are more successful in their relationships, which leads to greater social capital and more positive life outcomes (Brouillette, 2010). Children who garner more positive relationships with peers find attending school to be more enjoyable and will participate more readily in classroom activities (Locke et al., 2015). Class participation leads to students retaining more from their lessons (Brouillette, 2010). The arts can bolster students’ social competence and learning, and, as a result, bolster academic skills and future success. As described by Dewey, and supported by current research, the arts are effective for showing children how to utilize emotion and empathy in order to make social connections and improve their cognition (Brouillette, 2010; Goldblatt, 2006). Dewey posits that, through exploring the private self and through viewing the artworks of others outside of students' own cultural realms, emotionality and empathetic thinking is enhanced (Goldblatt, 2006). Research has shown that decision-making and other 
cognitive processes are affected by emotion, as defined by Brouillette (2010), who echoes Dewey's belief that academic skills go beyond rote learning and are affected by emotional ability and understanding of others' perspectives. Brouillette (2010) states that students who are more competent at understanding others' emotions often achieve more academically in the primary grades, supporting Dewey's idea that emotional understanding and empathy enhance and inform students' academic abilities in successes. Students who engage in arts curriculum gain a deeper understanding of their own emotional processes and, as a result, expand their cognitive abilities (Chen \& Liu, 2010). Students connect their experiences with their learning through creating personal art.

Arts and social development. The arts have been shown to improve social skills and social outcomes in children of all ages. In a review of recent research on the role of the arts in development, Brouillette (2010) found evidence that high-quality arts lessons lead to increased empathy, enhanced theory of mind, heightened conflict resolution skills, increased peer-to-peer interactions, and more positive problem solving. Children who are engaged in an activity or lesson are less likely to engage in detrimental behaviors (Brouillette, 2010). This may be particularly useful for children in low-income areas where behavioral outbursts are more common, due to life stressors related to nutrition, physical health, emotional health, issues with parents and siblings, and a multitude of other risk factors that can lead to maladaptive emotions and, by extension, behavior (Williams Shanks \& Robinson, 2013). Social regulation and control of social behaviors are necessary to being a functioning member of a classroom. Social regulation refers to a child's ability to interact positively with peers and adults (Buskirk-Cohen, 2015). 
Children in schools are around peers, teachers, administrators, and parents, and the ability to interact effectively with these different groups is beneficial to school success (Kalvin, Bierman, \& Gatze-Kopp, 2016). For many children, social and behavioral issues precipitate expulsion or suspension from school. If children cannot be a productive member of the classroom, they may be punished in ways that are detrimental to their future success (Isis, Bush, Siegel, \& Ventura, 2010).

Art gives children and adults a chance to connect in positive ways (Chen \& Liu, 2010). Teachers can give children who typically misbehave positive reinforcement through art activities, rather than negative attention through correcting behaviors on a daily basis. For children who are feeling anxiety or insecurity at school, art in a group setting can be inclusionary (Curry \& Kasser, 2005). As students share out their art or discuss others' art, they can learn to communicate positively about group accomplishments. The group setting allows for open communication about the process of creation and sharing of art. In this sense, facilitated, or teacher-guided, arts learning can lead to improved social outcomes (Rubin, 2016). Conversely, independent arts learning can lead to improved internal regulation outcomes (Rubin, 2016). Facilitated art-making in a school environment can lead to improved relationships between teachers and students by allowing both parties to develop social scripts for expressing emotionality through the arts (for example, by a student creating a piece of art and sharing its meaning with a teacher) (Brouillette, 2010).

Child-teacher relationships and child-parent relationships are strong factors relating to positive school outcomes (Williams Shanks \& Robinson, 2013). Art can be helpful as a 
process for parents or teachers to build one-on-one, positive relationships with children. Children and parents who share in feelings of frustration or helplessness can process their feelings together through art, which can lead to better relationship outcomes (Lee, 2015). To illustrate, Shin, Choi, and Park (2016) conducted a case study in a home setting focusing on the relationship between a mother and her 10-year-old son. Their relationship was strained, with the son stating the mother scared him and the mother admitting to feeling lost in her parenting and feeling guilty and anxious about being a parent. Through art-making, the mother was able to reflect on her own parenting style and change how she interacted with her son by expressing and exploring feelings, resolving suppressed inner conflicts, gaining confidence in her self-expression, and using her joint experiences with her son as a catalyst for change and self-reflection. Mother and son finding common ground through the production of art can translate to a classroom setting where a teacher may be having trouble connecting with a student. If a student is seen as frequently “causing problems," a teacher may be less empathetic to a child's struggle or point of view (Khadar, Babapour, \& Sabourimoghaddam, 2013). Knowing that children cannot always help their behavior, and finding positive ways to channel a student's behavior, can help teachers to build relationships with their students (Isis, Bush, Siegel, \& Ventura, 2010). If a child is prone to behavioral outbursts, art experiences can help to calm the child down and make the child's behaviors more manageable. To illustrate, if a child is frequently hitting in the classroom, a teacher can give her clay to punch or squish into shapes when she is feeling angry. If a teacher previously viewed a student as a problem student and frequently had only negative interactions with the student, having art as a 
bridge between them could be crucial to positive interaction. If the teacher can see the child in a different light, they can begin to build more positive interactions and trust with the student.

Art gives teachers and students a low-risk forum in which to build and develop positive interactions. Chen and Liu (2010) focus on teachers who are having difficulty connecting with their students. Teacher attitude regarding implementation of art as a communication tool is imperative. Teachers with more access to art-making trainings and materials can better utilize art to communicate with their students (Rubin, 2016). If teachers are focused on positive interactions and relationships with students, then art lessons are better received (Chen \& Liu, 2010). Teachers can utilize arts with learners at all levels. Some beneficial practices that teachers can utilize include creating art and sharing it out, structured and unstructured coloring, use of clay, and acting out scenarios. The arts allow for one-on-one interactions with students in a nonacademic realm, creating an open environment for emotional sharing and support. Teachers who are given training in art education have another tool for classroom management and connection with their students. As explained by Dewey, students are expected to learn practical skills as well as emotional skills, as education is meant to teach children how to exist in their society, culture, and world (as cited in Goldblatt, 2006).

In fact, school is a primary intervention for children who may need special services or help in development in different domains (Klorer \& Robb, 2012). Given that children in the United States are required to attend school, the great majority of children have access to the resources offered by the school environment. For this reason, having a solid 
intervention plan for children who will inevitably come to the classroom and need extra help is imperative. Arts are a common ground between teachers, typically developing students, and atypically developing students (Sitzer \& Stockwell, 2015). It is a nonthreatening and approachable way for students to express their needs and feelings and connect with others (Isis, Bush, Siegel, \& Ventura, 2010). Having different tools and methods for teaching makes the school day run more smoothly and builds more positive outcomes for children and teachers alike.

Peer relationships are crucial for children's positive outcomes (Buskirk-Cohen, 2015). Strengthening peer relationships can lead to friendships, which allow for development of emotional security, validation, intimacy, helpful behaviors, and support systems (Perryman, Moss, \& Cochran, 2015). Evidence suggests that art-heavy programs with peers have a positive effect on children’s social outcomes (Buskirk-Cohen, 2015). Research suggests that, if children are able to develop strong social bonds, they are able to maintain and build their own social competence in a classroom environment (Isis, Bush, Siegel, \& Ventura, 2010). Teachers often encourage prosocial behaviors, such as helping peers in the classroom. If children feel happier in the classroom and have better relationships with their peers and teacher alike, they are more likely to engage in behaviors that are helpful rather than hurtful (Locke et al., 2015). Art teaching practices such as creating art and then sharing, can build sustained bonds between students and peers or teachers. As supported by Dewey's theory, when students create emotions-based art and share out to peers, they are given the chance to empathize with others in the classroom (Goldblatt, 2006). If students can see the perspectives of others, they may 
become more understanding of different viewpoints (Goldblatt, 2006). Allowing for an environment for open, emotional sharing can create a community environment wherein students feel safe with each other and with their teacher. Brouillette (2010) reviews research which states that art-making is a social process in that children rely both on their own intentions in their art-making and the positive or negative responses of their peers. In this sense, creating art in a group setting is necessary for positive self-regard and continuation of artistic practices, but also for opportunities for social interaction and learning.

Arts and emotional development. Art can enhance different areas of development for children (Pesso-Aviv, Regev, \& Guttmann, 2013), including emotional well-being. Children use art to explore and express their fears and desires (Brouillette, 2010). Children may draw a character on a page that is constructed from their own imagination, but is imagined with real human emotions, desires, and motivations. As supported by Dewey, creating a story around a piece of art allows for children to experience empathy and explore theory of mind (as cited in Goldblatt, 2006). Being in control of the guided art-making process (sitting down, following steps, planning outcomes) allows children to gain control over their own behaviors in the classroom (Isis, Bush, Siegel, \& Ventura, 2010). If given the tools, children may learn to control and focus their emotional energy on a fun, low-pressure task (creating art) and translate it to the higher-pressure task of controlling emotions within classroom experiences. Through the psychotherapeutic process of sublimation, which refers to taking emotions and expressing them through a task or product, children can channel their emotions into the art-making process (Rubin, 
2016). Ability to regulate and control emotions allows children to absorb and retain information and control negative behaviors (Isis, Bush, Siegel, \& Ventura, 2010). Children, particularly children who live in poverty, can have differing avenues of emotional regulation development, some of which are not adaptive for success in a school environment. If children are feeling negative emotions and insecurity at school, they are less likely to learn and feel like they are part of the school community (Locke et al., 2015).

School can be an emotionally charged place, as students are expected to follow rules and behave with peers. Students who live in poverty may experience socio-emotional challenges such as enhanced stress, anxiety, and feelings of low self-worth in response to school performance (Kalvin, Bierman, \& Gatze-Kopp, 2016). Many children have trouble explaining their feelings using words, but art can allow children to explain themselves visually (Rubin, 2016). They can show a physical object, painting, song, or play that explains their feelings without feeling the pressure of expressing themselves emotionally through speech. School curriculum is developed to teach students how to externalize thoughts and create tangible products. As explained by Dewey's theories of arts in education, students are expected to learn about how the world works from school but are not expected to learn about themselves and how they fit into the world itself (Goldblatt, 2006). Artistic expression teaches students how to turn their attention inward and explore perceptions, feelings, moods, and emotional responses, all of which are often automatically triggered and experienced. Brouillette (2010) posits that, for children, the arts are a unique and rarely encouraged experience that helps children to recognize these 
unconscious shifts in mood and consciously affect or change them through art. The skill of learning what emotions are occurring and using that information to affect future responses is key to executive function, school success, and future life satisfaction (Winsler, Kim, \& Richard, 2014).

Unlike speech therapy for children who struggle with speech, or physical therapy for children who struggle physically, art can help children who struggle with their social and emotional skillset but can also be enjoyed by the whole class. Children do not feel singled out for being in "therapy," but are learning social and emotional skills alongside their peers in a relaxed way. Working on activities that all children in the classroom can succeed at and enjoy is beneficial for the harmony of the classroom environment. For the teacher, having all of the children feel as though they can succeed at the same activity allows for a more fluid classroom with fewer behavioral hiccups and diversions (Perryman, Moss, \& Cochran, 2015). To address the potential for classroom fluidity, an 18-year long interaction between 8 Head Start programs and art therapy graduate students showed the potential for art practices in a school setting to have a positive effect on emotional development (Klorer \& Robb, 2012). The Head Start children participated in weekly art activities and were then observed for social-emotional changes such as increased impulse control, peer interaction, self-worth, and attention regulation. The results of the study were qualitative, utilizing self-report and questionnaires. The results show positive changes in child outcomes. "Verbal communication" was mentioned as a positive change in the survey responses from Head Start teachers and coordinators 33\% of the time, and "Impulse control" was mentioned 26\% of the time. Klorer and Robb 
(2012) show a link between expression through art and expression through words. The researchers also show a connection between control and decision-making during art activities and the ability to maintain emotions, temper, and behaviors throughout non-artmaking times.

Students who engage in problem behaviors may be reacting to environmental factors beyond their control, such as family processes that result from parental socioeconomic status (Hosokawa \& Katsura, 2017). As stated by Dewey’s theory, art creation gives children control over their own creative process and, by extension, their environment (Goldblatt, 2006). If teachers guide children in the basic rules of art creation and allow children to explore creatively to create a product of their own design, children may learn how to manage their own behaviors within a basic rule framework (Isis, Bush, Siegel, \& Ventura, 2010). This is similar to the expectations of a classroom, where there are basic rules to follow but individual responsibility for how to behave within this framework. As children in preschool draw or paint, they are both creating and speaking aloud about what they are drawing, regardless of whether they are alone or with others (Brouillette, 2010). This social and egocentric speech eventually merges into an inner dialogue, which is leads to control of behavior within the classroom environment (Winsler, Kim, \& Richard, 2014). As stated by Dewey, art leads to independence, self-direction, responsibility, and taking charge of the creative process (Goldblatt, 2006). As children take charge of their artistic processes, they may transfer these skills to their daily classroom behavior management as well. 
Children who struggle with managing instances of negative behavior may be more likely to face negative school outcomes, which can diminish the potential for academic growth and future job success (Locke et al., 2015). Although farther in the future, and a result of more complicated chain of events and experiences, continued struggles with positive social and emotional development can contribute to suspension and expulsion. Early intervention is necessary in order to reduce the risk for these outcomes later in school and to give children a more positive perception of their individual roles in the classroom environment. Miami-Dade County Public Schools have been involved in integrating art practices to manage behavior in their schools since 1979. The administrators of the school system have focused their attention on children with emotional and behavioral issues (Isis, Bush, Siegel, \& Ventura, 2010). Isis, Bush, Siegel, and Ventura (2010) reflect on the successes and limitations of the art therapy program in the Miami-Dade school district. Before the arts program was created, Miami-Dade County Public Schools had high drop-out rates and instances of students being diagnosed as emotionally disturbed due to behavior challenges in the classroom. The program specifically targets students with emotional and behavioral challenges and focuses on providing counseling, art therapy, and family support services. After implementing the arts-centered curriculum, students showed lower anxiety levels and increased selfconfidence, and were less likely to drop out of school. Tactics, such as creating a dropout prevention mural to improve accountability and community involvement or creating imagery which serves as an expression of test anxiety, allowed students to conquer their fears and desires by using visual expression (Isis, Bush, Siegel, \& Ventura, 2010). The 
visual expression of daily life from a personal point of view aligns with Dewey's belief that art can be used in education to tell a personal story and create community involvement (Goldblatt, 2006).

\section{Poverty and Development}

Early childhood is the foundation on which children build future academic, social, and emotional skills, and living in poverty puts children at risk for poor school performance (Williams Shanks \& Robinson, 2013). There is need for intervention for groups that may be at risk for missing or not achieving social and emotional milestones (Fantuzzo et al., 2007). Differences in social-emotional growth may lead to less school success. Less school success may lead to poorer life outcomes. Poor life outcomes may lead to more poverty (Williams Shanks \& Robinson, 2013). This cycle continues for children living in poverty if there are no interventions in place to break it. Locke et al. (2015) posit that context-inappropriate anger and aggression in the classroom puts children at risk for social isolation and negative peer outcomes. Children who live in poverty are more likely to engage in these context-inappropriate behaviors in order to achieve social goals. Children who show context-inappropriate behavior are less likely to build and maintain positive peer relationships and are therefore at risk for negative social outcomes in the classroom. The more successful that children are at social and emotional understanding and control, the more likely they are to show positive growth and learning in a classroom environment (Locke et al., 2015).

Children are reliant on their parents’ or caregivers’ access to resources. Families living in poverty cannot often or may not be able to afford the same quality of food, 
education materials, healthcare, and extracurricular activities as children in higher income brackets (Williams Shanks \& Robinson, 2013). Families living in poverty are more likely to experience familial conflict (Anthony, Anthony, Glanville, Naiman, Waanders, \& Shaffer, 2005). Higher family conflict leads to higher stress and anxiety levels in children (Hosokawa \& Katsura, 2017). Higher stress and anxiety leads to higher rates of internalizing and externalizing behaviors (Kalvin, Bierman, \& Gatzke-Kopp, 2016). Emphasis is on academic outcomes rather than school-readiness skills can lead to higher stress and anxiety levels and, as a result, higher levels of context-inappropriate behavior (Locke et al., 2015).

Over time, preschool expectations have shifted to be more heavily based in curricular outcomes and less invested in cognitive and school-readiness skills (Fantuzzo et al., 2007). As preschool shifts to curricular focus and away from social and emotional focus, children who live in poverty are starting at a more vulnerable socio-emotional level than their peers, showing higher levels of aggression which may lead to social isolation, peer rejection, and victimization (Locke et al., 2015). National surveys of kindergarten teachers show that children, and more often children living in poverty, are not entering kindergarten with the social-emotional skills and behavioral control that is necessary for functioning in classrooms from kindergarten and beyond (Fantuzzo et al., 2007). Although social and emotional skills seem to take a secondary spot to academic achievement, regulatory skills and prosocial behaviors protect children from social maladjustment, thus improving their ability to participate in school (Hosokawa \& Katsura, 2017). Without the ability to control their behaviors and engage in socially 
meaningful interactions, children may struggle to learn effectively or, in a sense, learn how to learn. Children living in poverty, who are already facing difficulties associated with home to school connection, nutrition, trauma, and a host of other risk factors, are set up for even further school delay if school is not providing them with social and emotional strategies to succeed.

Since children living in poverty are already starting from a different social and emotional level from their peers, developing these skills in school may be an issue of fairness and equity. Different interventions must be enacted to make access to social and emotional learning accessible for all students, regardless of background. Preschool is a notable time for intervention, as preschool is the time when teachers prepare children for the academic and social-emotional expectations of kindergarten and beyond. Because the arts and arts education are accessible and easy to implement, they are a way to provide equitable social and emotional learning experiences to all children in the classroom, regardless of socioeconomic status. Children who live in poverty are at-risk for starting at a less adaptive social-emotional level than their peers, but the arts can provide more opportunities for equity in education. Art can be used as an intervention for children who may be experiencing difficulties at home or who may not have access to art materials in their homes (Rubin, 2016). Giving all children the same resources allows for those children who do not have resources available to them at home to be able to participate in learning in an equitable way.

Children who live in poverty are more likely to exhibit negative behaviors (Holtz, Fox, \& Meurer, 2015). Children who regulate their behavior more effectively are more 
likely to feel positively about their learning, control their attention, and maintain positive social interactions (Locke et al., 2015). Students who regulate their behavior effectively are more likely to collaborate with peers to complete tasks, whereas children who struggle with self-regulation may face social isolation and peer rejection (Locke et al., 2015). Students who show lower levels of aggression are more effective at listening and engagement in academia. Children who are disengaged are not able to effectively learn information in a school setting (Fantuzzo et al., 2007). Children who experience poverty are more likely to show signs of aggression and academic disengagement as a reaction to life stressors (Holtz, Fox, \& Meurer, 2015). Therefore, children who live in and experience poverty are less equipped to learn and succeed in a traditional school environment.

Overall, research has shown significant benefits in social, emotional, and behavioral development for children when the arts are implemented in the classroom. Since federal budget cuts and state funding concerns lead to diminished arts programs (California Alliance for Arts Education, 2005), children are excluded from learning opportunities such as those offered by arts education. It is important to utilize lessons which improve areas of social-emotional development and lead to greater academic success, particularly for children who are at risk for lowered social-emotional outcomes due to their income level.

\section{Study Goals}

This study posits that there may be quantifiable connections between arts education and socio-emotional and behavioral outcomes for preschool children (ages 3 to 5). One 
method that has been recognized as a valuable and cost-efficient way to identify social and emotional functioning across a large number of children is the use of behavior rating scales (Lidz, 2003). Children's overall success in the school environment can be measured using such scales which ask questions regarding how children behave with other children, with adults, and on their own. Assessing prosocial and antisocial behaviors can show how children within low-income environments behave in the classroom. For this reason, a behavior rating scale for preschoolers will be used to provide some quantitative data on social and emotional factors. Teacher surveys will be implemented along with the rating scale to explore results of the program that may not be encapsulated by the behavior rating scale's standardized questions. Surveys will give insight on what the program does well, where the program can improve, and possible next steps for the program. Surveys will allow for teachers to report the areas where their students are either succeeding or needing more support.

The purpose of the study is to explore potential connections between improved social skills and behavior after an arts program is implemented in two low-income preschool classrooms. The study will measure social and emotional factors before and after an art program is brought to two preschool classrooms at the same school site to determine whether or not arts implementation has any benefits on socio-emotional development for low-income children. It will also attempt to determine the specific social and emotional skills in which these changes occur. This study explores three major research questions: 1) Does arts education help to improve general adaptation in the classroom for at-risk children?; 2) Does arts education help to mitigate social, emotional, and behavioral 
issues?; and 3) Does arts education improve certain emotional and social factors more than others? 
Chapter 4

\section{Methods}

\section{Participant Population}

The subject population of this study includes 46 preschool students (two classrooms, Room 2 and Room 3, with 24 and 22 children in each respectively), aged 3- to- 5-years old, in the Redwood City School District in California. In the San Francisco Bay Area, where the Redwood City School District is located, the cost of living is 53\% higher than the national average (Start Class, 2016). The regional median income for the San Francisco Bay Area is \$92,094 annually (Data USA, 2018). Families in the Redwood City School District are at greater risk for poverty due to high cost of living in the San Francisco Bay Area.

The students attend Garfield Child Development Center, a satellite of the child development centers within the Redwood City School District. Two classrooms participated in this study: Room 2 and Room 3. Room 2 had 24 students total, with 11 girls and 13 boys. Room 3 had 22 students total, with 12 girls and 10 boys. Room 3 had 24 students, but one student was out of the classroom for 3 of the 6 weeks of the program and did not give consent, and another student was transferred to a different classroom while the study took place. Both classrooms had students receiving Individualized Education Plans. Room 2 had two children with IEPs for speech, and Room 3 had one child with an IEP, also for speech. No subjects were cognitively impaired, visually impaired, physically impaired, or have language/hearing difficulties that would require the need for special consent provisions. Although 96.9\% of the children at Garfield 
identified as Hispanic and were in Spanish-speaking families, instruction took place in the classroom in both English and Spanish, so the children did not require any translated materials (Start Class, 2015). The consent forms sent home to parents were translated to Spanish for those parents who prefer Spanish to English.

Garfield Child Development Center has a total number of 78 students (40 male, 38 female). Seventy students speak Spanish as their home language, four have English as their home language, two have Arabic as their home language, and two have an unknown home language. There are 71 Hispanic/Latino students, three White students, and four students of unknown ethnicity. These numbers align with the Garfield Elementary statistics, with higher male population and high English-language-learner population. There are three classrooms at Garfield CDC. This study employs two of the three classrooms. Overall, at Garfield CDC, 6.4\% are five years old ( $\mathrm{n}=5), 69.2 \%$ are four years old $(n=54)$, and $24.3 \%$ are three years old $(n=19)$. The two target classrooms together have 23 males and 23 females. Within the two target classrooms, $17.4 \%$ are five years old $(n=8), 63 \%$ are four years old $(n=29)$, and $19.5 \%$ are three years old $(n=9)$.

Garfield CDC is an annex to Garfield Elementary. The demographic data for Garfield Elementary is similar to the demographic data for the CDC, as many of the families whose children attend the CDC also have children who attend the elementary school. Elementary school data outlines the family statistics of the surrounding community. Forty percent of students at Garfield Elementary receive free or reduced lunch (Start Class, 2016). In order to qualify for free or reduced lunch, family income must be under an annual $\$ 21,590$. Within the child development center, the demographics are similar to 
those of the elementary school it is attached to. All of the students receive lunch and twice-a-day snack. Children do not bring their own lunches or snack.

Of the population at Garfield Elementary School, 96.9\% identify as Hispanic (Start Class, 2016). Garfield Community School is located in Menlo Park, wherein a typical school consists of $46.4 \%$ Hispanic students. Garfield has a significantly higher number of Hispanic students than schools in the surrounding area. In California as a whole, schools have an ethnic composition of 53.7\% Hispanic students (Start Class, 2016). Garfield has a significantly higher Hispanic population than the state average. The high Hispanic population is related to the high immigrant population in Redwood City. Refer to Table 1 for Overall Garfield CDC Demographic Data. 
Table 1

Garfield CDC Classroom Demographic Data

\begin{tabular}{lcccc}
\hline \multicolumn{1}{c}{ Factor } & $\begin{array}{l}\text { Rooms 2 } \\
\text { and 3 }\end{array}$ & Room 2 & Room 3 & $\begin{array}{r}\text { Rooms } \\
\text { and 3 (\%) }\end{array}$ \\
\hline Students & 46 & 24 & 22 & 100 \\
Boys & 23 & 13 & 10 & 50 \\
Girls & 23 & 11 & 12 & 6.5 \\
IEPs & 3 & 2 & 1 & 19.5 \\
3 Years Old & 9 & 5 & 4 & 63 \\
4 Years Old & 29 & 14 & 15 & 17.4 \\
5 Years Old & 8 & 5 & 3 & \\
\hline
\end{tabular}


Teachers. The two classrooms each have four teachers: One lead teacher, two assistant teachers, and one 4-hour teacher who works for only part of the day. Room 2 has three participating teachers. The 4-hour teacher in Room 2 is the researcher, who did not complete the rating scales or help with the program due to potential conflict of interest. Room 3 also has three participating teachers, because the 4-hour teacher in Room 3 was not present during the arts program in the morning and was therefore not able to assess or assist with the program. The lead teachers in Room 2 and Room 3 have completed their AA and AS, respectively. Both teachers have a Site Supervisor level Child Development Permit per the California Commission on Teacher Credentialing. The teacher in Room 3 serves as the Site Supervisor for the three classrooms onsite. The assistant teachers have varying amounts of units towards or possession of an Associate's degree in Child Development, and varied possession of Assistant Teacher level permits per the CCTC. The lead teacher in Room 2 is bilingual, instructing in English and Spanish. The assistant teachers in Room 2 instruct in English and Spanish, as well. In Room 3, the lead teacher instructs in only English, and the assistant teachers teach in both English and Spanish. The three teachers in each classroom (lead teacher and two assistants) worked together to complete the rating scales and guide the students through the arts program. See Table 2 for Garfield CDC Demographic Data. 
Table 2

Garfield CDC Teacher Demographic Data

\begin{tabular}{lcccc}
\hline \multicolumn{1}{c}{ Factor } & Total & Room 2 & Room 3 & Total (\%) \\
\hline $\begin{array}{l}\text { Total teachers } \\
\text { Total }\end{array}$ & 8 & 4 & 4 & 100 \\
participating & 6 & 3 & 3 & 75 \\
$\begin{array}{l}\text { Associate's } \\
\text { degree }\end{array}$ & 2 & 1 & 1 & 25 \\
$\begin{array}{l}\text { Units towards } \\
\text { degree }\end{array}$ & 3 & 2 & 1 & 37.5 \\
$\begin{array}{l}\text { Hold a CCTC } \\
\text { permit }\end{array}$ & 4 & 3 & 1 & 50 \\
\hline
\end{tabular}




\section{Materials and Devices}

The teachers in the classroom filled out the SCBE-80 (Social Competence and Behavior Evaluation), a 6-point Likert scale, to assess social and emotional factors both before and after program implementation. Questions on the assessment are rated from 1 to 6, with 1 being “Never,” 2 and 3 being "Sometimes,” 4 and 5 being “Often,” and 6 being “Always.” Assessment of the SCBE-80 has shown that it has high internal consistency, interrater reliability, and stability (LaFrenière, Dumas, Capuano, \& Dubeau, 1992). The SCBE-80 contains 80 total questions and 12 different ratings: eight Basic Scales and four Summary Scales. The eight Basic Scales include: Depressive-Joyful, Anxious-Secure, Angry-Tolerant, Isolated-Integrated, Aggressive-Calm, EgotisticProsocial, Oppositional-Cooperative, and Dependent-Autonomous. The four Summary Scales include: Social Competence, Internalizing Problems, Externalizing Problems, and General Adaptation. Each scale measures a different facet of social, emotional, and behavioral development in preschoolers. For each variable on the Basic Scale, ratings ranged from a possible 0 to 50 . Summary Scales show a different range of scores, which is detailed in the Summary Scales section.

Basic scales. The eight basic scales on the SCBE measure emotional adjustment. They are combined into three distinct groups: Overall adjustment, social interactions with peers, and social interactions with adults. Depressive-Joyful, Anxious-Secure, and Angry-Tolerant measure overall adjustment. Isolated-Integrated, Aggressive-Calm, and Egotistic-Prosocial measure social interactions with peers. Oppositional-Cooperative and Dependent-Autonomous measure social interactions with adults. Cronbach’s alpha was 
used to determine the psychometric properties of the eight basic scales. Angry-Tolerant, Aggressive-Calm, Egotistic-Prosocial, and Oppositional-Cooperative had reliability over .7, and Depressive-Joyful, Anxious-Secure, Isolated-Integrated, and DependentAutonomous had lower reliabilities ranging from .47 to .66.

Depressive-Joyful. The Depressive-Joyful scale measures affect and mood. The questions associated with this measure ask if the student is generally cheerful, if they smile often, or if they are often withdrawn. Children with higher scores are more Joyful, and children with lower scores are more Depressive. Scores can range from 0 to 50, with 0 being the furthest towards Depressive and 50 being the furthest towards Joyful. This scale is scored from 10 different questions, with possible response scores ranging from 05.

Anxious-Secure. The Anxious-Secure scale measures comfort and security in the classroom environment. Questions associated with this scale ask if the child is selfconfident, if they make eye contact when speaking, or if they feel inhibited in a group. Higher scores relate to security and lower scores relate to anxiety. Scores can range from 0 to 50, with 0 being the furthest towards Anxious and 50 being the furthest towards Secure. This scale is scored from 10 different questions, with possible response scores ranging from 0-5.

Angry-Tolerant. The Angry-Tolerant scale measures children's reactions to challenging situations in the classroom and their ability to negotiate with group settings. Some questions that relay to the Angry-Tolerant results ask if children scream or yell easily, whether they adapt easily, or if they whine or complain often. Lower scores relate 
to anger and higher scores relate to higher levels of tolerance. Scores can range from 0 to 50, with 0 being the furthest towards Angry and 50 being the furthest towards Tolerant. This scale is scored from 10 different questions, with possible response scores ranging from 0-5.

Isolated-Integrated. The Isolated-Integrated scale measures how active the child is in the social activities of the classroom. Questions for this section include how often other children seek to play with the child who is being assessed, if the child works easily in groups, and whether the child is inactive when play is occurring. Higher scores show higher levels of integration, whereas lower scores show more isolation. Scores can range from 0 to 50 , with 0 being the furthest towards Isolated and 50 being the furthest towards Integrated. This scale is scored from 10 different questions, with possible response scores ranging from 0-5.

Aggressive-Calm. The Aggressive-Calm scale measures how a child relates to his or her social surroundings, how he or she reacts to peers and adults, and his or her adjustment in group settings. Questions for this section include if the child negotiates conflict with other students, if they hit, bite, or kick other children, and if they are attentive to younger children. Higher scores show higher levels of calmness and lower scores show more aggression. Scores can range from 0 to 50 , with 0 being the furthest towards Aggressive and 50 being the furthest towards Calm. This scale is scored from 10 different questions, with possible response scores ranging from 0-5

Egotistic-Prosocial. The Egotistic-Prosocial scale evaluates how much empathy a child shows towards peers. Questions in this section express issues of seeing other 
children's perspectives, sharing toys, making games competitive, or getting upset when a teacher attends to another child. Higher scores show higher levels of prosocial behavior and lower scores show more egotistic behavior. Scores range from 0 to 50, with 0 being furthest towards Egotistic and 50 being furthest towards Prosocial. This scale is scored from 10 different questions, with possible response scores ranging from 0-5.

Oppositional-Cooperative. The Oppositional-Cooperative scale assesses how compliant children are with the requests of adults and peers in their social environment. Questions in this section include whether children accept compromise, help with everyday tasks, oppose teachers' suggestions, or are defiant when reprimanded. Higher scores show higher levels of oppositional behavior and lower scores show more cooperation in the classroom. Scores range from 0 to 50, with 0 being furthest towards Oppositional and 50 being furthest towards Cooperative. This scale is scored from 10 different questions, with possible response scores ranging from 0-5.

Dependent-Autonomous. The Dependent-Autonomous scale evaluates how much children rely on others in their environment to solve problems or soothe themselves. Some questions in this section include whether the child takes initiative in new situations, is persistent in solving his or her own problems, or is clingy to the teacher in novel situations. Higher scores show more autonomy and lower scores show more dependence. Scores range from 0 to 50 , with 0 being furthest towards Dependent and 50 being furthest towards Autonomous. This scale is scored from 10 different questions, with possible response scores ranging from 0-5. 
Summary scales. The four summary scales combine the scores of the basic scales to express overall adaptation in the classroom environment. Cronbach's alpha was used to determine the psychometric properties of the four summary scales. Social Competence, Internalizing Problems, Externalizing Problems, and General Adaptation all had reliability of .7 or higher.

Social Competence. Social Competence combines the eight positive scores on the Basic Scales (joyful, secure, tolerant, integrated, calm, prosocial, cooperative, and autonomous) in order to measure positive social functioning in the classroom. Higher scores show more effective socialization in the classroom environment. Scores can range from 0 to 200. This scale is taken from adding up 8 different scales, with possible scores ranging from $0-25$.

Internalizing Problems. Internalizing Problems combines four of the negative scales on the Basic Scales (depressive, anxious, isolated, dependent) in order to assess overall anxiety, depression, fear, and isolation, or, how much the child internalizes their problems. Higher scores point to more comfort and security in the classroom and fewer internalized problems. Scores can range from 0 to 100. This scale is taken from adding up 4 different scales, with possible scores ranging from 0-25.

Externalizing Problems. Externalizing Problems combines four of the negative scales on the Basic Scales (angry, aggressive, egotistical, and oppositional) to assess overall behavioral struggles with children and adults in the classroom. This scale focuses on aggression, opposition, and anger, or, how the child externalizes their problems. Higher scores point to lower levels of behavioral outbursts and anger. Scores can range from 0 to 
100. This scale is taken from adding up 4 different scales, with possible scores ranging from $0-25$.

General Adaptation. General Adaptation is an overall summary of the results in all categories. It expresses the results of all SCBE categories, showing the combination of scores reflected as a single score. Higher scores show more effective social and emotional integration into the classroom overall. General Adaptation score can range from 0 to 400 .

\section{Culminating Teacher Survey}

The classroom teachers consented to and completed a culminating survey containing questions summarizing their experiences with the program, suggestions for future programs, and whether or not the program fit into existing curriculum. The culminating survey was handed to teachers at the same time as the posttests. The culminating survey collects some qualitative data about how the arts program worked from the teachers' perspective and asks about future considerations for follow-up research on arts programs in schools. Questions on the survey included whether the program fit in with existing curriculum, if the program was enjoyable, if teachers would want to continue the program, and if the teachers saw any positive outcomes or negative outcomes, improvements or decreases in skills or behavior. Teacher responses were tallied and sorted into four sections: Self-Management of Behavior, Emotional Adjustment, Social Adaptation, and Enjoyment of the Arts. Room 2 returned 3 of 3 teacher surveys, and Room 3 returned 2 of 3 teacher surveys. One survey was not returned due to illness of one of the teachers. Culminating survey responses can be found 
in the Results section. The Art in Action Special Scope Arts Pilot Culminating Survey can be found in the Appendices.

\section{Student Interview}

A journalism intern with Art in Action was present in the classroom during the program. On the last day of the program, for both classrooms, the intern brought a small whiteboard with the prompt, “Art Makes Me Feel...” written on it and asked the students to draw how they were feeling under the words. He also asked the students to tell him how art made them feel. These questions were intended for the purpose of an online article through Art in Action, but the responses indicated the emotional responses of the students as a result of the arts program. Students' responses were sorted into the same four categories as the teachers' responses: Self-Management of Behavior, Emotional Adjustment, Social Adaptation, and Enjoyment of the Arts. "Art Makes Me Feel” data can be found in the Results section.

\section{Art in Action}

This study teamed with the nonprofit company Art in Action based in Menlo Park, California, who provided the curriculum used for the lessons. Art in Action provides art lessons to students who do not have arts programs at their schools. It was founded in 1982 with the intent to fight against Proposition 13 in California, which reduced property taxes and led to lower spending per student in California schools (Art in Action, 2018). As schools cut their budgets, arts programs across the state were cut as well. Art in Action became a nonprofit organization in 1999. Art in Action serves public, private, and charter schools in rural, suburban, and urban settings. Previous studies have been 
completed with Art in Action. The John W. Gardner Center for Youth and their Communities at Stanford University spent a year studying Art in Action to assess the success of the curriculum and to determine some potential impacts on the communities who receive Art in Action lessons (Biag, Raab, \& Hofstedt, 2015). The study used interviews, focus groups, document reviews, and lesson observations to assess 12 Kindergarten- through- $8^{\text {th }}$ grade schools of differing socioeconomic status and ethnic makeup that were either currently using Art in Action curriculum or had previously used Art in Action curriculum (Biag, Raab, \& Hofstedt, 2015). The researchers found that regardless of how the program was implemented, all respondents had a positive view of the program and thought that it was beneficial for the children receiving it. Biag, Raab, and Hofstedt (2015) report that Art in Action curriculum fostered new connections, notably, connections between students, their peers, and their schools. Biag, Raab, and Hofstedt (2015) indicate that Art in Action created spaces that allow for creativity, and in having these spaces, students could express themselves in different ways and feel pride, ownership, joy, and engagement with school. Bringing high-quality arts instruction to preschoolers may produce similar results. Art in Action's mission statement declares the importance of creativity for success in the modern workforce, and states that the company works to close the achievement gap by providing arts education as an equitable service for all children (Art in Action, 2018). The nonprofit teaches more than 70,000 students, trains around 3,000 teachers, and works with 500 schools and organizations throughout the United States. The curriculum offered by Art in Action is typically used in elementary and middle school settings. This is the first time that Art in Action curriculum has been 
taught to preschoolers, and the first study of this curriculum in a low-income preschool setting.

Teaching and volunteers. The researcher recruited two volunteers. There was one female volunteer and one male volunteer, both of which had previous experience with young children. One volunteer had worked in summer camps and the other had worked with children through church volunteer opportunities. Both had interest in learning art instructional strategies and gaining teaching experience. A technology reporting intern for Art in Action also assisted with preparations before teaching the classes and interviewed children about their experiences after the program was complete. He was present for both the Tuesday and the Friday sessions. At the end of the program, he wrote on a small whiteboard, "Art makes me feel”, and asked the students to fill in their answers. Their answers have been transcribed in the Results section of this thesis as additional, qualitative, social-emotional data about the children's perceptions of the art education experience.

Curriculum. The Art in Action curriculum features a variety of media including oil pastel, graphite, collage, paint, and paint with corks and sponges. Each lesson is designed around a different artist and piece of art from history. The curriculum spans from Kindergarten to eighth grade. However, since this study employed preschoolers, the Art in Action team made decisions on which lessons to pick from the Kindergarten curriculum and edited these lessons to be effective for preschool students. These edits included shortening the lesson period to 30 minutes rather than an hour and reducing the time given to the students to sketch out their ideas before creating the final product. Due 
to time constraints, new curriculum specifically developed for a preschool population could not be created. The lessons themselves were chosen for having less complexity and more sensory elements in order to make the experience process-based rather than product-based. Although the students were creating a "product", they were encouraged by the docents to make their art look however they wanted it to look. Six lessons were chosen, one for each week of the program. The lessons, in chronological order, were: Grant Wood/American Gothic, Vincent Van Gogh/Sunflowers, Wassily Kandinsky/Lines of Signs, Byzantine Mosaic/The Court of Empress Theodora, Utagawa Toyohiro/Four Accomplishments, No. 2, and Henri Rousseau/Virgin Forest with Setting Sun.

Each lesson followed the same general outline. First, the docent presented the artist and their style with an explanation of things to look for within the painting (for example, line, color, or value). Second, the docent provided an introduction to the specific project and how it relates to the original art. The students then moved to their small group tables and completed a sketch of plans or particular elements of the project. Once the sketch was completed, then there was a final work period for the students to complete their own art wherein the docent walked around to assist, guide, and encourage creativity and individuality. Art in Action utilizes an online portal for training and access to teacher notes, curriculum descriptions, and general questions for the docents who teach their programs. Art in Action's docents are community volunteers who receive a series of trainings on what the curriculum is and the steps of teaching it to a class. Sometimes, the classroom teachers themselves will teach the Art in Action curriculum from the curriculum descriptions provided on the online portal. The online portal is for the 
volunteers to access information about the coming lesson and learn how to teach the information before coming in to the Art in Action office for official lesson training. All curriculum was posted beforehand on the online portal for the docents to access in addition to their weekly in-house training.

Twelve separate boxes were delivered, one at the beginning of each lesson (one box per docent, once a week for six weeks). The boxes were packed and materials were prepared in-house at Art in Action before each lesson. Inside each box was a large, printed example of an art piece from history and materials to create a project that was based on the work. The boxes each contained different art media, such as paint, construction paper, paint brushes, oil pastels, and pencils/paper for a sketch before the main project. Some lessons incorporated drawing tips or examples of how to draw particular objects that the students could choose to refer to if they needed assistance. The lessons each focuses on a particular piece of art or artist. The students are taught different art-making skills related to each piece (how to draw a face from American Gothic, how to mix paint and leave a 3-dimensional layer of paint on the paper from Van Gogh, etc.).

\section{Design}

This study used a non-experimental pretest-posttest design to measure within-group and between-group changes over time. The pretest and posttest had the same measure (The SCBE-80), with the SCBE-80 serving as the dependent variable, and engagement in the art program being the independent variable. Age, classroom, gender, English language competence, and number of years attending the preschool program were used as 
control variables, to rule out any confounding explanations for children's reactions to the art program.

\section{Procedures}

Before starting the program, the research statement and consent forms were distributed by the researcher and classroom teachers in both English and Spanish. Using a random number generator, a 4-digit, nonconsecutive number was assigned to each child for the purpose of confidentiality. Any statistical comparison between pretest and posttest was made from matching numbers rather than matching names.

After pretest measures were completed for all participating students, two volunteer docents recruited by the researcher and trained by Art in Action began teaching a series of lessons, 1 day a week (one classroom every Tuesday from 9:30 am to $10 \mathrm{am}$, the other every Friday from 10:30 am to $11 \mathrm{am}$ ), 30 minutes a day, from Art in Action's previously established, Kindergarten-focused curriculum. The docents received a 15-minute training in-house at Art in Action before each lesson, picked up a box containing the art supplies for the day's lesson, and came to the classroom to teach. 3 weeks into the 6-week program, the two volunteer teachers switched between the two classrooms to reduce any potential confounding factors associated with the docent. The SCBE-80 posttest, was completed after the 6-week program ended. Teacher surveys were distributed to all 6 teachers at the same time as the posttests were distributed and returned. Teacher surveys were examined for frequency of response and category of response (social, emotional, or behavioral) in order to obtain information to inform future Art in Action programs and future research on arts education and its impact on classroom and social behavior. 


\section{Chapter 5}

\section{Results and Discussion}

The main goal of data analysis was to compare changes in students’ social competence and general adaptation in the classroom between pretest and posttest. First, change scores were calculated by subtracting pretest scores from posttest scores, and a paired samples t-test and an independent samples t-test was performed to determine whether there were significant differences between the two classrooms. After running an independent samples t-test, there were no statistically significant differences between the two classrooms. The change in scores on the eight basic scales and the four summary scales of the SCBE-80 were relatively homogeneous to each other, with neither room showing extreme change. Because the rooms had no significant differences as indicated by the independent samples t-test, both rooms could be combined to create a larger sample size of 46 students (23 male, 23 female). With a larger sample, that resulted from combining both rooms, paired t-test results showed statistically significant changes in Social Competence $(M=-11.92, S D=25.91), p=.002$ and Egotistic-Prosocial $(M=$ 5.83, $S D=6.86), p=.001$. Internalizing Problems and Oppositional-Cooperative, while not rising to the level of significance at .05, were both at $p=.067$, suggesting that a larger sample size may have indicated significant findings. Depressive-Joyful, Anxious-Secure, Angry-Tolerant, Isolated-Integrated, Dependent-Autonomous, Externalizing Problems, and General Adaptation were not significant. Refer to Table 4 for paired samples t-test results. 
The SCBE-80 scoring booklet (Franiere \& Dumas, 2003) states that scores ranging from 22 to 40 on the eight basic scales (Depressive-Joyful, Anxious-Secure, AngryTolerant, Isolated-Integrated, Aggressive-Calm, Egotistic-Prosocial, OppositionalCooperative, and Dependent-Autonomous) indicate a "Low Average” overall result. Scores ranging from 85 to 133 on Social Competence, 63 to 84 on Internalizing Problems, 65 to 88 on Externalizing Problems, and 216 to 302 on General Adaptation indicate the overall "Low Average” result for the four summary scales.

The mean pretest scores for Depressive-Joyful $(M=34)$, Anxious-Secure $(M=$ 34.22), Angry-Tolerant ( $M=32.48)$, Isolated-Integrated $(M=33.59)$, Aggressive-Calm ( $M=32.20)$, Egotistic-Prosocial $(M=28.33)$, Oppositional-Cooperative $(M=33.85)$, and Dependent Autonomous $(M=30.70)$ indicated that mean scores on all eight basic scales fell into the range of "Low Average”, indicating that, overall, students may benefit from socio-emotional intervention. Mean pretest scores on Social Competence $(M=103.33)$, Internalizing Problems $(M=76.89)$, Externalizing Problems $(M=81.50)$, and General Adaptation $(M=259.35)$, all fell into the range of "Low Average” as well. The mean scores on the four summary scales also indicated the potential need for intervention in the classroom.

On the eight basic scales, some children had lower scores than others. For use in this study, as indicated in the above section, children who had a "Low Average" score or lower were tallied to show what percentage of the class exhibited socio-emotional needs before the program began. To narrow results further, students who scored 34 and under were also tallied, to get a sense of how many children were scoring below average on the 
basic scales and thus exhibiting more socio-emotional issues. On the eight basic scales, a score of lower than 40 indicates some behavioral concern. A score under 34 indicates great behavioral concern. For Depressive-Joyful, $82.6 \%$ of students scored 40 or below (n $=38$ ), and $58.7 \%$ of students scored 34 or below $(\mathrm{n}=27)$. For Anxious-Secure, $84.8 \%$ of students scored 40 or below $(n=39)$, and $63 \%$ of students scored 34 or below $(n=29)$. For Angry-Tolerant, $82.6 \%$ of students scored 40 or below $(n=38)$, and $58.7 \%$ of students scored 34 or below ( $\mathrm{n}=27$ ). For Isolated-Integrated, $89.1 \%$ of students scored 40 or below $(n=41)$, and $56.5 \%$ of students scored 34 or below $(n=26)$. For AggressiveCalm, $84.8 \%$ of students scored 40 or below $(n=39)$, and $56.5 \%$ of students scored 34 or below $(n=26)$. For Egotistic-Prosocial, 93.5\% of students scored 40 or below $(n=43)$, and $76.1 \%$ of students scored 34 or below $(\mathrm{n}=35)$. For Oppositional-Cooperative, $65.2 \%$ of students scored 40 or below $(n=30)$, and $58.7 \%$ of students scored 34 or below ( $n=$ 27). For Dependent-Autonomous, 93.5\% of students scored 40 or below $(n=43)$, and $78.3 \%$ of students scored 34 or below $(n=36)$.

On the four summary scales, scores at or below 112 on Social Competence, 78 on Internalizing Problems, 78 on Externalizing Problems, and 269 on General Adaptation indicate a "Low Average.” For deeper analysis, a “Low” score was also considered. This "Low" score is at or below 84 for Social Competence, 68 for Internalizing Problems, 62 for Externalizing Problems, and 225 for General Adaptation and was determined by locating the low scores as shown in the SCBE Booklet (Freniere \& Dumas, 2003). On Social Competence, $65.2 \%$ of students scored 112 or below $(n=30)$, and $30.4 \%$ of students scored 84 or below $(\mathrm{n}=14)$. On Internalizing Problems, 56.5\% of students 
scored 78 or below $(n=26)$, and $19.6 \%$ scored 68 or below $(n=9)$. On Externalizing Problems, $41.3 \%$ of students scored 78 or below $(\mathrm{n}=19)$, and $15.2 \%$ scored 62 or below $(n=7)$. On General Adaptation, 65.2\% scored 269 or below $(n=30)$, and $15.2 \%$ scored 225 or below $(n=7)$. These results suggest that the students in the classroom are, in general, at a low average or low level of socio-emotional functioning and could benefit from an intervention. See Table 3 for the pretest scores for each basic scale and summary scale and Table 4 for paired samples t-test data. 
Table 3

Pretest Scores

\begin{tabular}{|c|c|c|c|c|c|}
\hline Measure & $M$ & $\begin{array}{l}\text { Number in } \\
\text { "Low } \\
\text { Average" } \\
\text { range }\end{array}$ & $\begin{array}{l}\text { Percentage } \\
\text { in “Low } \\
\text { Average" } \\
\text { range }\end{array}$ & $\begin{array}{l}\text { Number in } \\
\text { "Low" } \\
\text { range }\end{array}$ & $\begin{array}{l}\text { Percentage in } \\
\text { "Low" range }\end{array}$ \\
\hline $\begin{array}{l}\text { Social } \\
\text { Competence }\end{array}$ & 103.33 & 30 & 65.2 & 14 & 30.4 \\
\hline $\begin{array}{l}\text { Internalizing } \\
\text { Problems }\end{array}$ & 76.89 & 26 & 56.5 & 9 & 19.6 \\
\hline $\begin{array}{l}\text { Externalizing } \\
\text { Problems }\end{array}$ & 81.50 & 19 & 41.3 & 7 & 15.2 \\
\hline $\begin{array}{l}\text { General } \\
\text { Adaptation }\end{array}$ & 259.35 & 30 & 65.2 & 7 & 15.2 \\
\hline $\begin{array}{l}\text { Depressive- } \\
\text { Joyful }\end{array}$ & 34.00 & 38 & 82.6 & 27 & 58.7 \\
\hline Anxious-Secure & 34.22 & 39 & 84.8 & 29 & 63 \\
\hline Angry-Tolerant & 32.48 & 38 & 82.6 & 27 & 58.7 \\
\hline $\begin{array}{l}\text { Isolated- } \\
\text { Integrated }\end{array}$ & 33.59 & 41 & 89.1 & 26 & 56.5 \\
\hline Aggressive-Calm & 32.20 & 39 & 84.8 & 26 & 56.5 \\
\hline $\begin{array}{l}\text { Egotistic- } \\
\text { Prosocial }\end{array}$ & 28.33 & 43 & 93.5 & 35 & 76.1 \\
\hline $\begin{array}{l}\text { Oppositional- } \\
\text { Cooperative }\end{array}$ & 33.85 & 30 & 65.2 & 27 & 58.7 \\
\hline $\begin{array}{l}\text { Dependent- } \\
\text { Autonomous }\end{array}$ & 30.70 & 43 & 93.5 & 36 & 78.3 \\
\hline
\end{tabular}


Table 4

Combined Data Paired Samples t-Test

\begin{tabular}{|c|c|c|c|c|}
\hline Measure & $M$ & $S D$ & $t$ & $p$ \\
\hline $\begin{array}{l}\text { Social } \\
\text { Competence }\end{array}$ & -13.46 & 27.84 & -2.25 & $.002 * *$ \\
\hline $\begin{array}{l}\text { Internalizing } \\
\text { Problems }\end{array}$ & 4.39 & 15.87 & .33 & .067 \\
\hline $\begin{array}{l}\text { Externalizing } \\
\text { Problems }\end{array}$ & .11 & 17.25 & -1.04 & .97 \\
\hline $\begin{array}{l}\text { General } \\
\text { Adaptation }\end{array}$ & -9.02 & 40.13 & -2.14 & .13 \\
\hline Depressive-Joyful & -1.15 & 6.24 & -1.49 & .22 \\
\hline Anxious-Secure & -.54 & 6.70 & -.83 & .59 \\
\hline Angry-Tolerant & .00 & 8.45 & -1.04 & 1.00 \\
\hline $\begin{array}{l}\text { Isolated- } \\
\text { Integrated }\end{array}$ & .48 & 6.47 & .62 & .62 \\
\hline Aggressive-Calm & -1.30 & 7.15 & -1.12 & .22 \\
\hline $\begin{array}{l}\text { Egotistic- } \\
\text { Prosocial }\end{array}$ & -4.04 & 7.94 & -4.17 & $.001 * * *$ \\
\hline $\begin{array}{l}\text { Oppositional- } \\
\text { Cooperative }\end{array}$ & -2.07 & 7.47 & -1.55 & .067 \\
\hline $\begin{array}{l}\text { Dependent- } \\
\text { Autonomous }\end{array}$ & 6.030 & 6.030 & -.679 & .72 \\
\hline
\end{tabular}




\section{Difference in Outcomes by Gender}

In order to examine whether changes in social-emotional outcomes varied by gender, multivariate analysis of variance (MANOVA) was performed on the change scores (posttest-pretest) for the 8 outcome variables. No significant effects were detected. The independent variable was gender, as indicated on SCBE-80 forms, and the dependent variables were the socio-emotional outcomes of the SCBE-80 pretest and posttest.

\section{Difference in Outcomes by Age}

After running a MANOVA, it was clear that there were no significant differences in data due to age effects. The majority of students $(n=29)$ were four years of age, with the rest being three $(n=9)$ and five $(n=8)$ years old. The group was relatively homogeneous; thus, age effects may not have been as easily detectable as they may have been with a larger sample size. The analysis could not detect any effects from normative developmental processes, but future studies should collect data on normative developmental changes to rule this out more definitively. Use of a control group could provide more data on normative developmental processes by providing data on how children's scores change in the absence of an intervention.

\section{Student Interview Results}

The digital journalism intern at Art in Action asked the students a few short questions about how art made them feel. The intern asked students open-ended questions about art and recorded their responses. In response to the prompt, “I like art because..”, students responded with: I have a chance to do something different; I can use glitter; I can paint with my fingers. In response to the prompt, “art makes me feel..”, students responded 
with: Happy because I can imagine becoming an artist; Like myself because I can make mistakes; Loved because I like to draw people who are important to me; Invincible! I can be a policeman, firefighter, or even a superhero!; Awesome!; Like I need to wash my hands; Relaxed, I can focus on drawing what I want. The students' answers provide some qualitative data on how they were feeling during and after the process. The responses point to the art program being fun, new, and important for social and emotional outcomes. Children reported feeling relaxed, focused, happy, invincible, able to make mistakes, able to feel like themselves, and able to enjoy the materials they were working with. All responses show positive feelings about the arts program. The act of interacting with the intern appears to have allowed for social channels to be opened and emotional states to be expressed. The "art makes me feel" interview questions provided some unexpected insight into the students' interpretation of the program and how it made them feel.

The responses were categorized based on 4 major elements of the study: SelfManagement of Behavior, Emotional Adjustment, Social Adaptation, and Enjoyment of the Arts. The responses that correspond to Self-Management of Behavior are, "Like I need to wash my hands” and, “Relaxed, I can focus on drawing what I want.” The responses that correspond to Emotional Adjustment are, "Happy because I can imagine becoming an artist”, "Like myself because I can make mistakes", "Invincible! I can be a policeman, firefighter, or even a superhero!”, and “Awesome!”. The response that corresponds with Social Adaptation is, "Loved because I like to draw people who are important to me," and the responses that correspond with Enjoyment of the Arts are, "I 
have a chance to do something different," "I can use glitter," and, "I can paint with my fingers".

The highest frequency of responses was in the Emotional Adjustment category. Students reported emotions more often than they reported social changes. However, the SCBE data shows growth in Social Adaptation rather than in Emotional Adjustment. These results could point to some potential issues with using only qualitative data to make inferences about social and emotional change. Although students may be experiencing higher frequency of social change than emotional change, the manner in which they report these changes is in the form of how they are feeling. Also, the results from student interviews show a mismatch between how students view their experiences and how teachers observe children. The teachers noticed more social differences, while the students felt more emotional differences. This could point how emotionality informs social development and comfort in the classroom. It also could be because there were fewer child results than teacher results. Even further, it could be because the overall prompt was framed differently for the teachers than for the students. However, the results do provide some interesting data on the differences and similarities in teacher report and student report as a result of the same program. See Table 5 for frequencies and categories of student response. 
Table 5

Student Interview Results

\begin{tabular}{lc}
\hline \multicolumn{1}{c}{ Measure } & Frequency of Response \\
\hline Self-Management of Behavior & 2 \\
Emotional Adjustment & 4 \\
Social Adaptation & 1 \\
Enjoyment of the Arts & 3 \\
\hline
\end{tabular}




\section{Teacher Survey Results}

Teacher survey revealed positive outcomes from the arts program. All teachers answered that they were able to fit the Art in Action into their preexisting curriculum. The Redwood City School District follows assessment categories per the Desired Results Developmental Profile (DRDP), wherein there is a section for Visual and Performing Arts (VPA). One teacher reported that the arts program fit into the DRDP rating category for VPA and, therefore, enhanced her curriculum. All teachers reported that their students enjoyed the arts program, as was evidenced by their students’ facial expressions and behavior. All teachers reported that they would like to continue the Art in Action curriculum beyond the scope of the study, as the students had not had an experience with direct art instruction before. All teachers reported that they found the arts to be important to social and emotional development. Two of the teachers reported a need for instruction in smaller groups, rather than the whole class split into multiple tables. Future iterations of the preschool Art in Action curriculum may be more successful with focus on smaller groups of students for more behavioral control and learning opportunities. One teacher suggested that improvements could be made by extending the curriculum beyond the arts by including a literary element. For example, reading a book about Van Gogh and extending the knowledge of the artist into the project itself.

On reporting positive outcomes of the program, teachers reported that they saw children: Interacting with adults and other children successfully, following directions and making connections, building relationships with the volunteers, feeling free to combine colors or use different materials in making art, sharing materials with others, improving 
fine motor skills while using materials, counting pieces of paper for their collage to engage in math skills, engaging in color mixing as a science activity, getting excited about art, socializing with other people in the classroom more, and looking forward the next week of class. On reporting negative outcomes of the program, teachers reported difficulties with: Particular students who needed more direction, some of the paper being too large for the work area the children had access to, issues surrounding the art being less child-directed than may be appropriate for preschool, and the session being slightly long. In future Art in Action lessons for preschool, the time may need to be further adjusted to account for the age group, smaller materials or alternatives for amount of space provided may be necessary, and projects may need to be tweaked to be less teacher-directed or teacher-influenced, and more reflective of the child's own artistic vision and exploration.

Teachers were asked if they saw any improvements in their students' social, emotional, and behavioral factors. Teachers responded overwhelmingly that, yes, they did see a positive change in their students. One teacher reported that she saw students describing what they were doing, where they were going to put things on their artwork, and which colors they were using. She saw many conversations happening that were not teacher-facilitated. Another teacher reported that she saw the children who are sometimes quiet in the classroom or who do not always seek out interaction using the time to interact with teachers, volunteers, and other students. She reported that even the students who do not like to get messy still enjoyed the messy projects, and that the students were excited to share their final results with their teachers and docents. One teacher reported that she 
would like the preschool Art in Action program to continue in other schools. The program was a pilot for preschool outreach and can serve as an opportunity to develop curriculum that is specific to a low-income preschool population, wherein children do not get the same access to art materials and activities.

Teacher responses were tallied by frequency and categorized into four major sections. Each tally represents an instance where a teacher reported seeing behavioral evidence for the following measures: Self-Management of Behavior, Emotional Adjustment, Social Adaptation, and Enjoyment of the Arts. Teachers reported "Enjoyment of the Arts” most frequently, 13 times, citing that they saw their students having fun with the program and that they would like the program to continue. Teachers reported "Social Adaptation" nearly as frequently, at 12 times. The responses of the teachers align with the results of the study, as the teachers express seeing increased overall social adaptation and an increase in prosocial behaviors in the classroom. In this study, teacher report aligned with quantitative data to show similarities in change. See Table 6 for frequencies and categories of teacher response. 
Table 6

Teacher Survey Data

Measure

Frequency of Response

Self-Management of Behavior

1

Emotional Adjustment

1

Social Adaptation

12

Enjoyment of the Arts

13 


\section{Discussion}

The results of the analyses provide answers to the original three research questions. This study aims to answer three overarching questions: 1) Does art help to improve general adaptation in the classroom for at-risk children?; 2) Does art help to mitigate social, emotional, and behavioral difficulties?; 3) Does art improve certain social and emotional factors more than others? The results taken from the SCBE-80, teacher surveys, and student responses answer these research questions.

Research question 1 tests whether the change in general adaptation between pretest and posttest was significant. The two measures that indicate overall adaptation in the classroom are General Adaptation and Social Competence. Overall social competence did improve as a result of implementing an arts program in schools, but overall adaptation did not. Social Competence combines the positive social aspects of the scales (joyful, secure, tolerant, integrated, calm, prosocial, cooperative, and autonomous). General Adaptation is an overall summary score of global adjustment in the classroom, which is measured by combining the other three summary scores (Social Competence, Internalizing Problems, and Externalizing Problems) on the SCBE-80. Since Social Competence is a sum of the positive social, emotional, and behavioral factors on the SCBE-80, the significant change in scores from pretest to posttest shows that, in general, positive behavior improved in the classroom. While general adaptation did not improve, the General Adaptation score does not offer information on particular strengths or difficulties individual to each child. General Adaptation may be more likely to change significantly if some of the longer-term measures improve (such as Angry-Tolerant and 
Externalizing Problems, which may be a reaction to systemic issues related to poverty). The nonsignificant General Adaptation score reflects the fact that only some social and emotional measures showed significance. As described by Anthony, Anthony, Glanville, Naiman, Waanders, and Shaffer (2005), some aspects of classroom behavior are a result of ongoing stress in the home environment, and interventions which target school and home together may serve to improve overall General Adaptation more effectively. Intervening at only the school level may not provide an overarching intervention system for children who face daily stressors as a result of poverty. Social Competence combines the positive measures on the rating scale, with a higher score representing higher frequency of positive social behaviors. Improvement of Social Competence does, in fact, show that the arts program improved social outcomes for children within the classrooms.

Research question 2 explores whether the change in pretest and posttest overall was significant enough, and in the right areas, to define the arts program as successful. It can be concluded that the arts did improve Social Competence scores, and that overall social ability did improve after the implementation of the arts program. There was a change in prosocial behaviors in the classroom as well. Children and teachers reported feeling successful with social connection and deeper social connection through the course of the program through interview and survey responses. These reports were within the Teacher Surveys and the "art makes me feel" interviews. Overall, the increase of social connections and enjoyment in the classroom as observed by teachers shows that the arts program was successful in its purpose of affecting social, emotional, and behavioral competence. As reported by both teachers and students, these changes were noticeable 
and significant. The particular measures wherein there were significant changes (Social Competence and Egotistic-Prosocial) align with the Literature Review and hypotheses of this study, showing that positive social behavior does occur as a result of arts programs in group settings (Buskirk-Cohen, 2015). The measures with lower growth or significance may be more affected by a longer program or an individualized program. As noted earlier, group arts programs have different strengths from individual or one-on-one arts programs (Sitzer \& Stockwell, 2015). As evidenced by Sitzer and Stockwell (2015), group interventions develop prosocial and communication skills, but, as shown by Carsley, Heath, and Fajnerova (2015), independent, mindful coloring activities can reduce internalizing behaviors, such as anxiety and depression. Anxious-Secure, Integrated-Isolated, and Depressive-Joyful all may be improved by integrating individualized art alongside group-based art to reach multiple realms of socio-emotional expression.

Research question 3 explores whether some factors had more change than others. It appears that the arts education program did improve some SCBE-80 measures, with a statistically significant change in Social Competence and Egotistic-Prosocial and an almost significant change in Internalizing Problems and Oppositional-Cooperative. These results show that Social Competence and prosocial behaviors are both improvements as a result of the program. These results align with research showing that children are more likely to communicate their feelings and are more likely to cooperate with others in their classroom when exposed to a group arts program (Buskirk-Cohen, 2015). The nearsignificant findings in Internalizing Problems and cooperation in the classroom suggests 
that these areas may show some shift, as well, if the program is modified to include more independent art creation and analysis alongside home connections and interventions. Including these modifications would align with Dewey's belief that the arts are both an expressive activity and a teaching opportunity for internal reflection and growth (Goldblatt, 2006), and would express the potential benefits of including parents in the intervention as well. Including parents could allow for a connection between school and home, as evidenced in Biag, Raab, and Hofstedt's (2015) analysis of the strengths of the Art in Action program.

The least significant changes were in Externalizing Problems and Angry-Tolerant. Children still showed the same amount of negative behavioral outbursts and the same level of overall anger as they did at the start of the program. A longer program may affect long-term measures, since behavioral issues are often a result of systemic stress (due to low-income status, which is a factor that was not changed), and anger is generally a response to feelings of helplessness, which may also be related to low-income status (Holtz, Fox, \& Meurer, 2015). Including parents in the arts intervention may change some results surrounding anger and aggression, since parental socioeconomic status and marital disputes affect children's aggression levels (Hosokawa \& Katsura, 2017). 


\section{Chapter 6}

\section{Conclusion}

This study investigated three research questions: 1) whether the arts improve general adaptation for low-income students, 2) if art helps to mitigate social, emotional, and behavioral issues in the classroom, and 3) if art improves certain social, emotional, and behavioral factors more than others. The statistically significant change in overall social competence and prosocial behaviors in the classroom aligned with the original hypothesis that the arts do improve social, emotional, and behavioral outcomes for preschool children. Pretest scores showed low average and low scores on SCBE measures of socioemotional functioning. Although all measures did not improve significantly, there were improvements in areas that align with overall social competence and prosocial behaviors, which are both essential elements of a functioning classroom. The Teacher Survey results and “Art Makes Me Feel” results showed relationship building between peers and between students and docents, indicating that the program helps children to build relationships with their docents and with each other. The SCBE-80 pretest and posttest results showed strengthened Social Competence and prosocial behaviors, indicating that this relationship building and art-making process led to more positive feelings and behaviors in the classroom environment.

The near-significance of the results measuring change in internalizing problems and cooperative behavior in the classroom points to potential for future research. The least significant improvements occurred in anger and externalizing behaviors, both of which are connected to feelings of helplessness. This result may be a product of the low-income 
environment wherein the children live, but it could also be an indicator that there was simply not much change between pretest and posttest. The results for externalizing problems were already relatively high, with a mean score of 79, meaning that children in either classroom did not show particularly high instances of externalizing problems to begin with. The results for anger were slightly different, with a mean score of 32, showing that children in both classrooms showed relatively high instances of angry behavior and affect. The anger scores may be a focus of future research on how the arts could attempt to mitigate anger and encourage tolerance in the classroom. Although teachers, parents, and the general population know that the arts can be linked to better feelings and actions, self-report data and interview does not provide conclusive evidence of change in these factors. Employing SCBE-80 data collection allowed for numerical evidence to be collected. In pairing SCBE-80 results with survey data, the outcomes are clear: students do express a notable change in their feelings, social interactions, and behavior as a result of even a short arts education intervention.

The fact that all teachers reported seeing improvements is positive, but it also shows the importance of a variety of different data types. Results from the qualitative data analysis showed that teachers viewed the program as successful, and that children improved, but it does not say in which areas the children improved or by how much. Results from the quantitative data analysis showed that the children improved in very specific areas. Both types of data are essential, because the program cannot be fully successful unless the teachers also enjoyed it and saw it as beneficial or able be continually implemented. If the teachers did not like the program, it would not be viable 
for use. Since they did enjoy the program, however, it shows that the program itself was effective, along with the numerical data showing how much and it what areas it was effective. The reports from the students themselves proved to be a useful assessment tool, as the children could express how they were feeling about the program and about their own art-making outside of the teachers' opinions of how they were feeling. Both assessments originally used for this study were teacher-directed: the SCBE-80, as administered by teachers, and the Teacher Survey, which asked teacher opinions on the program. The inclusion of child interview from Art in Action's journalism staff allowed for a deeper look into how the students themselves were feeling. Student responses were positive, which showed that the arts did help students in their social, emotional, and behavioral outcomes.

It is notable that children showed observable changes in affect and behavior over the course of the program. All teachers reported seeing their students building relationships with each other and the docents in the classroom. Children were seen continuing the methods that they had learned in their art lessons. For example, in the Grant Wood/American Gothic lesson, children were taught ways of organizing features on a face by mapping where the different parts of the face are located on the head. After this lesson, children continued to use the skills they learned in order to draw faces. In this sense, the program taught some art techniques, but also helped the children to see everyday things in a different way and break a whole up into parts to make sense of it. As teachers saw the children utilizing their newly-learned art abilities, they responded positively to the learning process, which could result in more positive outcomes. 
The Art in Action model that is typically used involves bringing art boxes and curriculum to classroom teachers in order to help the teachers themselves utilize and implement the arts. The Art in Action model for this research utilized volunteers to bring the art supplies and teach the arts classes, but typically Art in Action advocates for teacher empowerment via providing arts resources and training. This has implications for future research, in that teacher training and interest in the arts holds a critical role in quality of student learning (Mcclure, Tarr, Thompson, \& Eckhoff, 2017). Specifically, Mcclure, Tarr, Thompson, and Eckhoff (2017) argue that teachers who are trained to teach the arts are more likely to see positive changes such as discovery, interaction, imagination, and relationship-building as a result of an arts program. Teachers’ enthusiasm, support, and ability to work as a team to implement art education creates stronger outcomes from such programs. This is why Art in Action training is useful for teachers, and why future Art in Action preschool programs may include a teacher training element as an alternative to the docent route.

However, the docent route did show some positive elements in the classroom. The students built relationships with the volunteers who came in every week. Art can be used as a catalyst for relationship growth. It was observed in this program, with children learning under positive guidance from the docents and positive responses to their art and the art-making process. Students looked forward to the program, but also to seeing the docents. Children sometimes used the docents as the subjects of their art; for the American Gothic/Grant Wood lesson, one student drew the docent as one of the two subjects on her paper. After the program concluded, students were asking where the 
volunteers were and were suggesting new times for the program to continue. The students observably looked forward to the program each week. The teachers hung the Art in Action projects up in the classroom to show parents what the children were making and to allow children to examine their own art.

\section{Limitations}

This study has some limitations. One limitation is the number of classrooms and, as a result, the number of subjects in the study. Since there were only 46 students in the sample, there may be some statistical data that could not be determined due to a small sample size and lack of power to detect change. Additionally, there was no control classroom, so instances of natural developmental trajectory could not be compared to the developmental trajectory of children who were exposed to the Art in Action program. Having a set of children with pretest and posttest results for the same time period but with no arts intervention would allow research to compare standard growth of social, emotional, and behavioral outcomes to growth of these outcomes when an arts program is used. The homogeneous nature of the classrooms also makes results difficult to apply to the general population. However, results can be applied to similar populations of lowincome preschool learners. Another limitation of this study is the length of the program. At only 6 weeks long, it may be hard to determine any effects of an arts program that could develop over a longer period of arts exposure. In some ways, the 6-week timeline shows that exposure to the arts for only a short period of time can have significant results on children, and that even a short period of an arts program can lead to significant 
change. It is important to consider, however, whether there would be change in more of the social, emotional, and behavioral areas if the program were longer.

Reliability concerns were a limitation, with Depressive-Joyful, Anxious-Secure, Isolated-Integrated, and Dependent-Autonomous showing low reliability. In the next steps, a modified version of the scale may be more reliable for indicating change in these measures. Another limitation of the study is the English comprehension of the teachers completing the assessments. The teachers in either classroom have varied levels of English comprehension, and answers on the assessments may have been affected as a result. Translated assessment materials would ensure that the teachers who are fluent in Spanish, with more limited English, are scoring the materials to the best of their ability and knowledge. There is a translated version of the SCBE-80 which may be useful for future studies with Spanish-speaking populations (Dumas, Martinez, \& LaFreniere, 1998). Also, the provided Art in Action curriculum is Eurocentric in nature, focusing specifically on art history from European culture. Since the subject population is majority Hispanic, a series of lessons focusing on Latino artists could provide positive results. Art in Action is already developing a series of lessons about Latino artists and art history. The program is still being created, however, and could not be utilized in this study due to being unfinished.

As per the teacher surveys, some tweaks could be made to the preschool program itself. Shorter instruction times, smaller groups, more open-ended materials, and a possible literary element could all be included to allow for more streamlined learning. The study was limited by time constraints and could not fully change the preschool 
curriculum for the population before the expected start date of the program. With more time to work on the curriculum, this study could be run again with different specifications for a preschool population. The data presented in this study, however, can inform future Art in Action curriculum development and improve outcomes if the nonprofit does choose to continue working in low-income preschools. Last, there was a period of time after the students' winter break where there were 6 children who were still on vacation. These students missed 1-2 full lessons of content and may not have had full exposure to the program in the same sense as the other students. Further study must be done using a control classroom and translated assessment materials.

\section{Strengths}

This study showed several strengths. The switch in docents halfway through the program controlled for any confounding factors around teaching style. Switching the docents allowed each classroom to experience each teacher’s method of teaching. Another strength was that the classrooms had significant similarities, with teachers showing equivalent levels of education, classes having equivalent gender and ethnic distributions, and IEP information aligning. Since there were no significant differences between the two classrooms, the data for the study could be considered as large group

data for 46 students overall, rather than as each classroom independently. Also, the statistically significant findings in prosocial behaviors and Social Competence can be generalized to other classrooms with similar ethnic makeup and income level. Finally, the study utilized both qualitative and quantitative data, for a more in-depth study of how the program worked for both students and teachers. Knowing how teachers felt in 
conjunction with data on the social, emotional, and behavioral measures of the students made for a comprehensive view of what was going on in the classroom as a result of the arts program.

\section{Future Research}

In looking forward, there are some additions that could be made to this study in order to find more conclusive data. Intervening at the home level in conjunction with the school level may serve to improve long-term outcomes, such as General Adaptation, AnxiousSecure, and Angry-Tolerant. As shown by Locke et al. (2015), anger and aggression in preschoolers can be a result of a stressful home environment. Finding ways to affect the home environment with an arts program may lead to more positive long-term outcomes. Parent involvement in the program could lead to more effective outcomes, as shown in the Biag, Raab, and Hofstedt (2015) study of Art in Action's effective practices. One of the effective aspects of Art in Action curriculum is the school-to-home connection, and future iterations of the preschool program could include parent involvement.

Another future consideration would be inclusion of translated SCBE-80 rating scales for the teachers. There is a Spanish version of the SCBE-80 that could be used by teachers who are more comfortable using Spanish over English. Having translated materials would allow teachers to make more calculated assessments of their students and counteract potential error due to misunderstanding or confusion over language. Future studies would employ a control classroom to examine how children's natural social, emotional, and behavioral development progresses over the same period of time without 
an arts program present. Comparing to a group without the program would allow for more accurate understanding of the significance of the results.

The near-significance in change in Internalizing Problems and cooperative behavior in the classroom could lead to future research. What effects do the arts have on internalizing problems and engaging in cooperative behavior, and how could the study be tweaked to accommodate these measures more effectively? A longer program, perhaps the usual 12 lessons that are offered by Art in Action, may target some of the longer-term measures that showed little or no change in this study. Having a longer research period would account for any missed class periods. Missing one or two class periods has a smaller effect when there are 12 class periods, versus missing one or two classes of 6 class periods. Having a longer program would also allow for researchers to test before, during, and after the program to measure change over time. Employing more subjects may also lead to more significant results in more or different areas. Combining group and individualized lessons in the same arts program or curriculum may also lead to more diverse results, as some social, emotional, and behavioral factors are more affected by working in a group and some are more affected by independent work. A last consideration would be measuring level of teacher training and involvement in the arts to see how the quality of arts instruction affects outcomes, and how teachers' views of the importance of the arts in education can affect student learning. 


\section{References}

Anthony, L. G., Anthony, B. J., Glanville, D. N., Naiman, D. Q., Waanders, C., \& Shaffer, S. (2005). The relationships between parenting stress, parenting behaviour and preschoolers' social competence and behaviour problems in the classroom. Infant and Child Development,14(2), 133-154. doi:10.1002/icd.385

Art in Action. (2018). Retrieved February 19, 2018, from https://artinaction.org/

Beh-Pajooh, A., Abdollahi, A., \& Hosseinian, S. (2018). The effectiveness of painting therapy program for the treatment of externalizing behaviors in children with intellectual disability. Vulnerable Children and Youth Studies,1-7. doi:10.1080/17450128.2018.1428779

Biag, M., Raab, E., \& Hofstedt, M. (2015). An Implementation Study of the Art in Action Program. Stanford, CA: John W. Gardner Center for Youth and Their Communities.

Brouillette, L. (2010). How the arts help children to create healthy social scripts: Exploring the perceptions of elementary teachers. Arts Education Policy Review, 111(1), 16-24. doi:10.1080/10632910903228116

Buskirk-Cohen, A. A. (2015). Effectiveness of a creative arts summer camp: Benefits of a short term, intensive program on children's social behaviors and relationships. Journal of Creativity in Mental Health, 10, 34-45.

California Alliance for Arts Eduction. (2005). Quality, equity and access: A status report on arts education in California public schools grades pre-k through 12. (Policy brief). Retrieved from http://www.artsed411.org/files/docs/briefingpaper05.pdf

Carsley, D., Heath, N. L., \& Fajnerova, S. (2015). Effectiveness of a classroom mindfulness coloring activity for test anxiety in children. Journal of Applied School Psychology, 31(3), 239-255. 
Castro, S., Granlund, M., \& Almqvist, L. (2015). The relationship between classroom quality-related variables and engagement levels in Swedish preschool classrooms: A longitudinal study. European Early Childhood Education Research Journal,25(1), 122-135. doi:10.1080/1350293x.2015.1102413

Chang, N., \& Cress, S. (2014). Conversations about visual arts: Facilitating oral language. Early Childhood Education Journal, 42(6), 415-422. doi:10.1007/s10643 013-0617-2

Chapman, J. I. (1998). Proposition 13: Some unintended consequences. Public Policy Institute of California: Occasional Papers.

Chen, I. J., \& Liu, C. C. (2010). Using drawing as intervention with children for in service preschool teachers. Journal of College Teaching \& Learning, 7(4), 1-8.

Curry, N. A., \& Kasser, T. (2005). Can coloring mandalas reduce anxiety? Art Therapy: Journal of the American Art Therapy Association, 22(2), 81-85.

Demographic Data, San Francisco, CA. (2015). Data USA. Retrieved from https://datausa.io/profile/geo/san-francisco-ca/

Dewey, J. \& Dewey, E. (1915). Schools of tomorrow. New York: E.P. Dutton.

Dewey, J. (1925). Human nature and conduct: An introduction to social psychology. New York: Modern Library.

Dewey, J. (1934). Art as experience. New York: Perigee.

Dewey, J. (1938a). Experience and education. New York: Collier.

Dewey, J. (1938b). Logic: The theory of inquiry. New York: Henry Holt. 
Dumas, J. E., Martinez, A., LaFreniere, P. J. (1998). The Spanish version of the Social Competence and Behavior Evaluation (SCBE)-preschool edition: Translation and field testing. Hispanic Journal of Behavioral Sciences, 20(2), 255-269. https://doi.org/10.1177/07399863980202008

Fantuzzo, J., Bulotsky-Shearer, R., McDermott, P. A., McWayne, C., Frye, D., \& Perlman, S. (2007). Investigation of dimensions of social-emotional classroom behavior and school readiness for low-income urban preschool children. School Psychology Review, 36(1), 44-62.

Goldblatt, P. F. (2006). How John Dewey's theories underpin art and art education. Education and Culture, 22(1), 17-34. doi:10.1353/eac.2006.0001

Holtz, C. A., Fox, R. A., \& Meurer, J. R. (2015). Incidence of behavior problems in toddlers and preschool children from families living in poverty. The Journal of Psychology: Interdisciplinary And Applied, 149(2), 161-174.

Hosokawa, R., \& Katsura, T. (2017). A longitudinal study of socioeconomic status, family processes, and child adjustment from preschool until early elementary school: The role of social competence. Child and Adolescent Psychiatry and Mental Health, 11. doi:10.1186/s13034-017-0206-z

Isis, P. D., Bush, J., Siegel, C. A., \& Ventura, Y. (2010). Empowering students through creativity: Art therapy in Miami-Dade county public schools. Art Therapy: Journal of the American Art Therapy Association, 27(2), 56-61.

Kalvin, C. B., Bierman, K. L., \& Gatzke-Kopp, L. M. (2016). Emotional reactivity, behavior problems, and social adjustment at school entry in a high-risk sample. Journal of Abnormal Child Psychology, 44(8), 1527-1541. doi:10.1007/s10802-016-0139-7

Khadar, M. G., Babapour, J., \& Sabourimoghaddam, H. (2013). The effect of art therapy based on painting therapy in reducing symptoms of oppositional defiant disorder (ODD) in elementary school boys. Procedia-Social and Behavioral Sciences, 84, 1872-1878. http://dx.doi.org/10.1016/j.sbspro.2013.07.051 
Klorer, P. G., \& Robb, M. (2012). Art enrichment: Evaluating a collaboration between head start and a graduate art therapy program. Art Therapy: Journal of the American Art Therapy Association, 29(4), 180-187.

LaFrenière, P. J., \& Dumas, J. E. (1995). The Social Competence and Behavior Evaluation-Preschool Edition. Los Angeles: Western Psychological Services.

LaFrenière, P. J., \& Dumas, J. E. (Ed). (2003). The Social Competence and Behavior Evaluation-Preschool Edition. Los Angeles: Western Psychological Services.

LaFrenière, P. J., Dumas, J. E., Capuano, F., \& Dubeau, D. (1992). Development and validation of the Preschool Socioaffective Profile. Psychological Assessment, 4(4), 442-450. http://dx.doi.org/10.1037/1040-3590.4.4.442

Lidz, C. S. (2003). Early childhood assessment. New York: John Wiley \& Sons.

Lee, S. Y. (2015). Flow indicators in art therapy: Artistic engagement of immigrant children with acculturation gaps. Art Therapy: Journal of the American Art Therapy Association, 32(3), 120-129.

Locke, R. L., Miller, A. L., Seifer, R., \& Heinze, J. E. (2015). Context-inappropriate anger, emotion knowledge deficits, and negative social experiences in preschool. Developmental Psychology, 51(10), 1450-1463.

Mcclure, M., Tarr, P., Thompson, C., \& Eckhoff, A. (2017). Defining quality in visual art education for young children: Building on the position statement of the Early Childhood Art Educators. Arts Education Policy Review, 118(3), 154-163.

Perryman, K. L., Moss, R., \& Cochran, K. (2015). Child-centered expressive arts and play therapy: School groups for at-risk adolescent girls. International Journal of Play Therapy, 24(4), 205-220.

Pesso-Aviv, T., Regev, D., \& Guttmann, J. (2013). The unique therapeutic effect of different art materials on psychological aspects of 7-to-9-year-old children. The Arts in Psychotherapy, 41, 293-301. 
Poverty in California. (n.d.). Public Policy Institute of California. Retrieved March 10, 2018, from http://www.ppic.org/publication/poverty-in-california/

Rubin, J. A. (2016). Approaches to art therapy: theory and technique. Philadelphia: Brunner-Routledge.

Shin, S. K., Choi, S. N., \& Park, S. W. (2016). A narrative inquiry into a mother-child art therapy experience: A self-exploration of the therapist and the mother. The Arts in Psychotherapy, 47, 23-30. doi:10.1016/j.aip.2015.09.001

Sitzer, D. L., \& Stockwell, A. B. (2015). The art of wellness: A 14-week art therapy program for at-risk youth. The Arts in Psychotherapy, 45, 69-81. doi:10.1016/j.aip.2015.05.007

Start Class: Garfield Elementary. (2015). Retrieved February 19, 2018, from http://public-schools.startclass.com///12515/Garfield-Elementary-in-Menlo-Park California

Tucker, J. (2017). California schools once again forced to tighten belts, weigh cuts. San Francisco Chronicle. Retrieved from https://www.sfchronicle.com/bayarea/article/California-schools-once-again forcedto-tighten-11042923.php

Williams Shanks, T. R., \& Robinson, C. (2013). Assets, economic opportunity and toxic stress: A framework for understanding child and educational outcomes. Economics of Education Review,33, 154-170. doi:10.1016/j.econedurev.2012.11.002

Winsler, A., Kim, Y. K., \& Richard, E. R. (2014). Socio-emotional skills, behavior problems, and Spanish competence predict the acquisition of English among English language learners in poverty. Developmental Psychology, 50(9), 2242-2254. doi:10.1037/a0037161

Yoshikawa, H., Aber, J. L., \& Beardslee, W. R. (2012). The effects of poverty on the mental, emotional, and behavioral health of children and youth: implications for prevention. The American Psychologist, 67(4), 272-284. doi: 10.1037/a0028015. 


\section{Appendix A \\ SCBE-80 Rating Scale}

Social Competence and Behavior Evaluation-Preschool Edition (SCBE)

Peter J. LaFreniere, Ph.D.

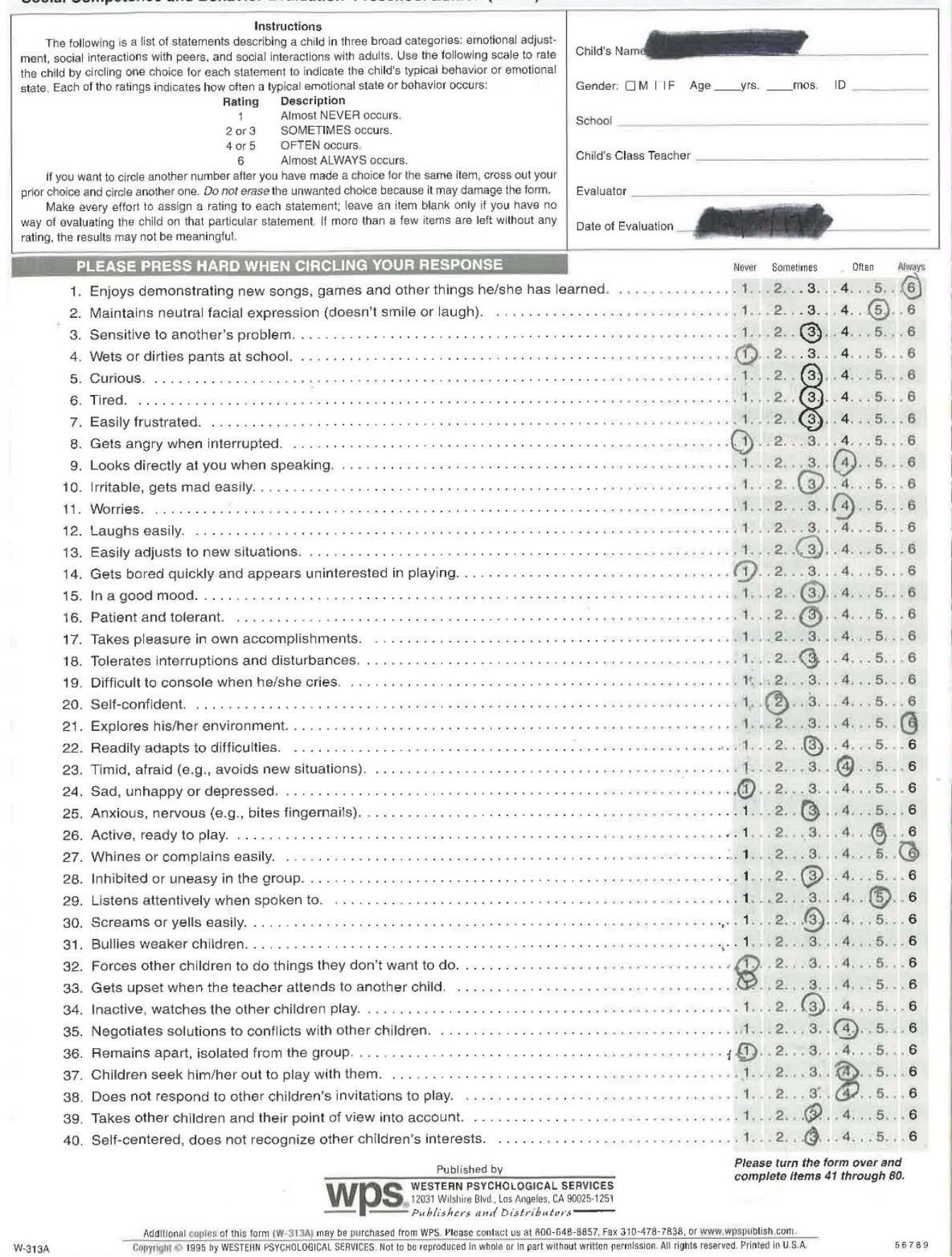


PLEASE PRESS HARD WHEN CIRCLING YOUR RESPONSE

41. Is involved wherever the children are having lots of fun, $\ldots \ldots \ldots \ldots \ldots \ldots \ldots \ldots \ldots \ldots, \ldots, \ldots 3 \ldots 4 \ldots 5 \ldots$.6

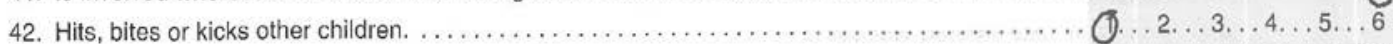

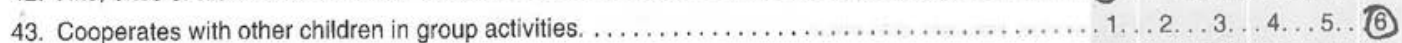

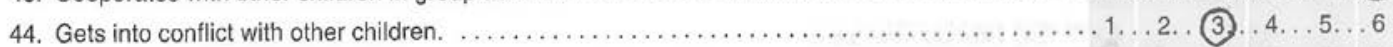

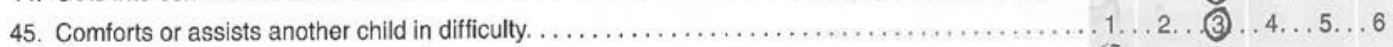

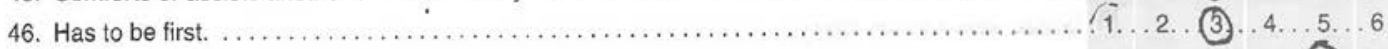

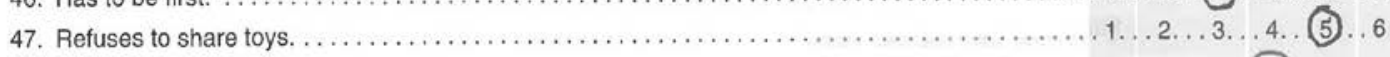

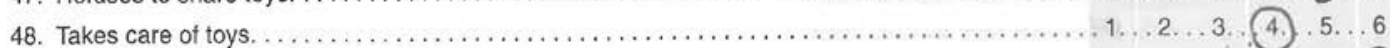

49. Doesn't talk or interact during group activities. . . . . . (6)

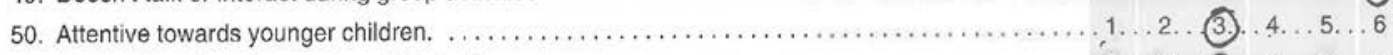

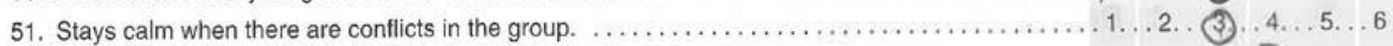

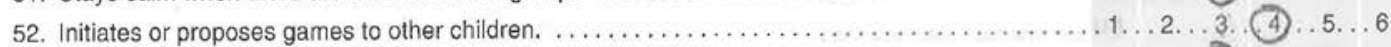

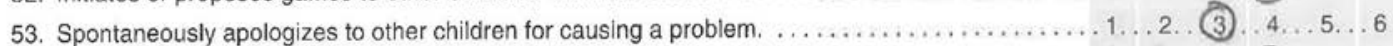

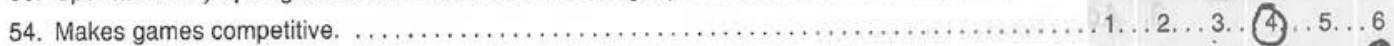

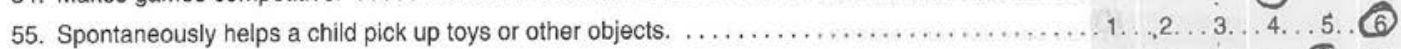

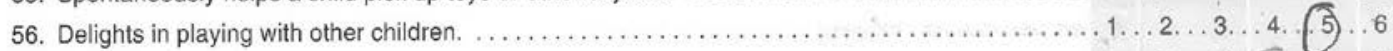

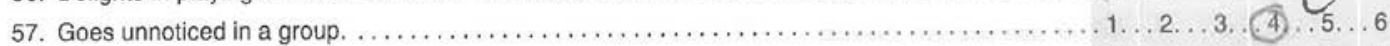

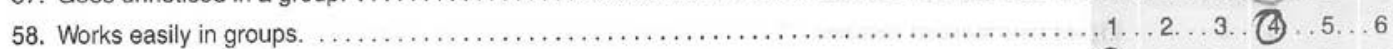

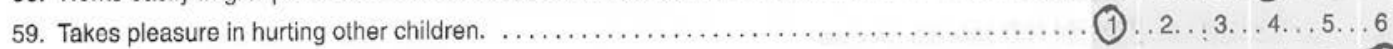

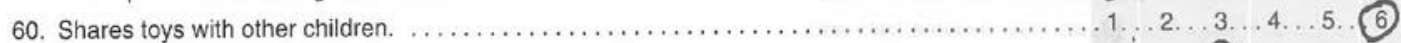

61. Recovers quickly when he/she falls or hurts self (doesn't cry very long) $\ldots \ldots \ldots \ldots \ldots \ldots \ldots 1 \ldots 2 \ldots$. 3., $4 \ldots 5 \ldots 6$

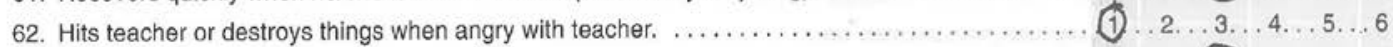

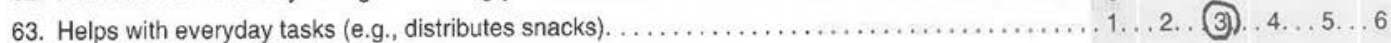

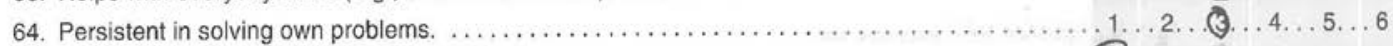

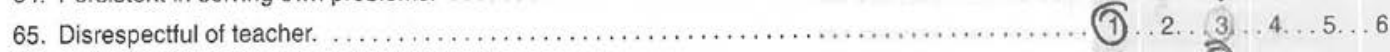

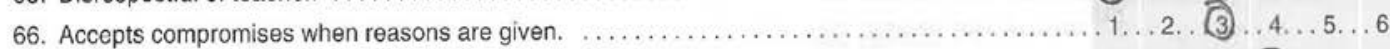

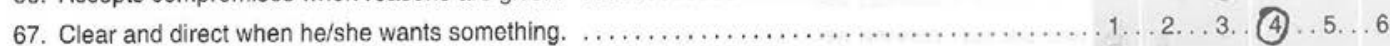

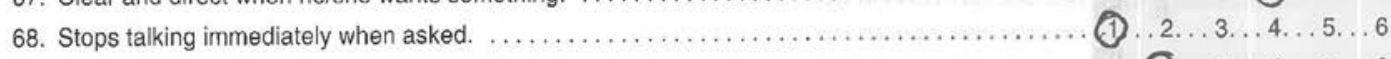

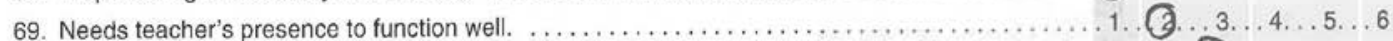

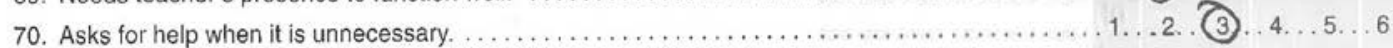

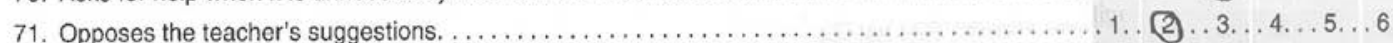

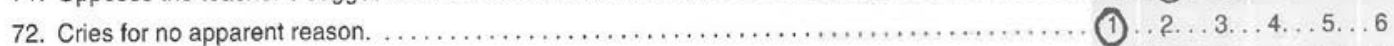

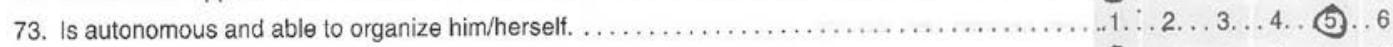

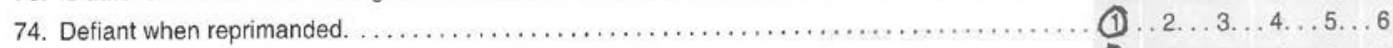

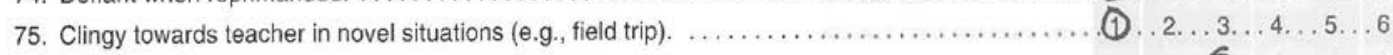

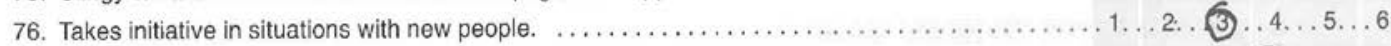

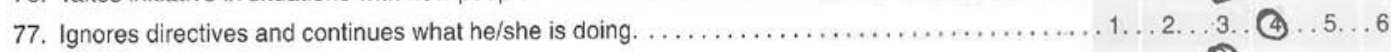

78. Accepts teacher's involvement in own activity. . . . . .

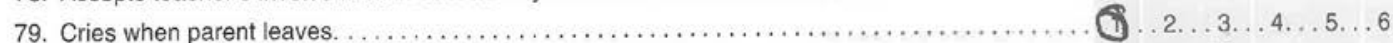

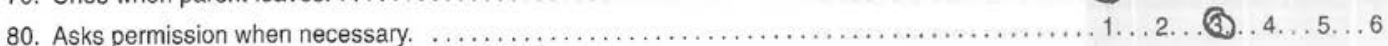


SCBE Scoring Sheet

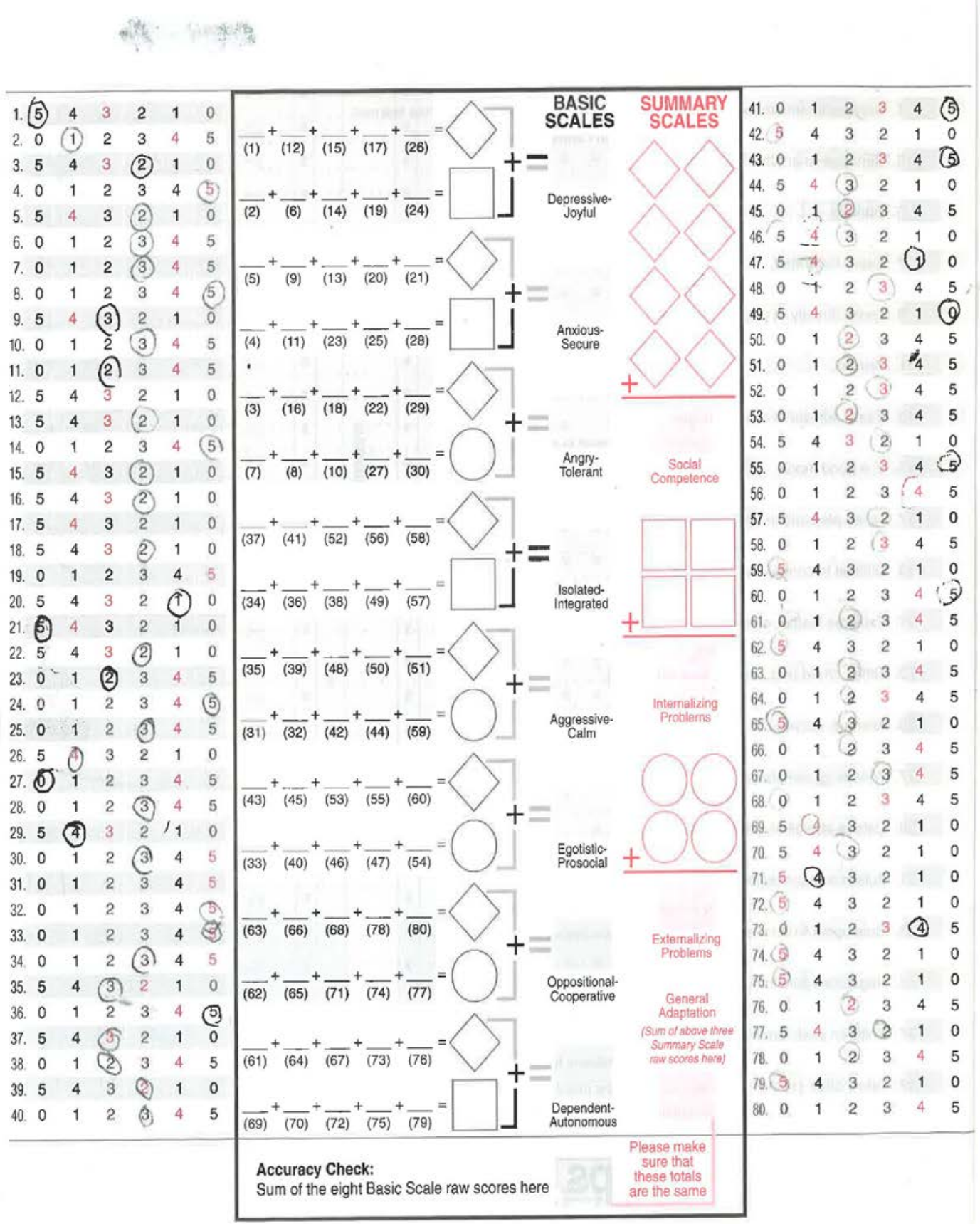




\section{Appendix B}

\section{Art in Action Special Scope Arts Pilot \\ Culminating Survey for Teachers}

Please answer the following questions to the best of your ability. All answers given will help to improve future iterations of this program, other Art in Action programs, and will contribute to future research in this field of study. Please do not write your name on this sheet in the interest of confidentiality. Thank you for your help and involvement with this study. We appreciate your hard work and cooperation through this process.

1. How well did the curriculum with Art in Action fit in with your pre-existing curriculum?

2. Was the program enjoyable for you? Please explain why or why not.

3. What suggestions do you have for this program?

4. Do you see yourself continuing this program in your classroom? Why or why not? 
5. What positive outcomes did you see from this program? Are there any positive outcomes for yourself, your students, or your school?

6. What negative outcomes did you see from this program? Are there any negative outcomes for yourself, your students, or your school?

7. Did you see an improvement in your student's social, emotional, and behavioral factors? If so, in what ways? If not, in what ways?

8. Is there any other information you would like the researcher to know? 